\title{
Risk Evaluation and Molecular Biomarkers Identification of Firefighter Suffering Lung Cancer Via the TCGA Database
}

Bin Bai ( $\sim$ Baibincom@163.com )

Tianjin Fire Research Institute https://orcid.org/0000-0002-3523-4371

Qinghao Meng

Tianjin Noraml University

\section{Research article}

Keywords: Competing endogenous RNAs (ceRNAs), firefighters, lung cancer, biomarker, PAHs, VOCs

Posted Date: May 29th, 2020

DOI: https://doi.org/10.21203/rs.3.rs-30114/v1

License: (c) (i) This work is licensed under a Creative Commons Attribution 4.0 International License.

Read Full License 
Title:

Risk evaluation and molecular biomarkers identification of firefighter suffering lung

4 cancer via the TCGA database.

5

6

Authors: BinBai ${ }^{1 *}$, Qinghao Meng ${ }^{2 *}$

Affiliations: Full information for each author

$8{ }^{1}$ Tianjin Fire Research Institute of MEM,

9 ORCID:0000-0002-3523-4317.

$10{ }^{2}$ College of Life Science, University of Tianjin Normal University,

11 ORCID:0000-0001-6323-9260

12 *BinBai and Qinghao Meng contributed equally to this work and should be considered as

13 co-first author.

14 Address for Correspondence:

15 BinBai, M.D.

16 Tianjin Fire Research Institute of MEM, Tianjin 300382, China

17 E-mail: Baibincom@163.com

18

19 Funding: This research was supported by Tianjin Fire Research Institute of MEM.

20

21 


\section{Risk evaluation and molecular biomarkers identification of}

25 firefighter suffering lung cancer via the TCGA database.

26 Abstract

27 To evaluate the risk of firefighters suffering lung cancer after a long-term career and 28 identify novel molecule biomarkers for evaluation, we tested the composition of 29 flame-resistance door combustion byproducts. The results showed that the main component of 30 combustion byproducts was PAHs and VOCs. The ceRNAs network showed that 26 mRNAs, 3118 miRNAs, and 141 lncRNAs were involved in the lung cancer process. Most of the 32 ceRNAs in our study could be affected by PAHs and VOCs. The Kaplan-Meier plots of 33 differentially expressed RNAs in the ceRNA network showed that 3 mRNAs, 4 miRNAs, and 34 13lncRNAs have a relationship with the survival time of lung cancer patients. We 35 recommended that mRNA COL1A1, CCBN1, and PFKP; miRNA hsa-miR-143, hsa-miR-183, 36 hsa-miR-144, hsa-miR-372 and hsa-miR-373; lncRNA UCA1, TTTY16, LSAMP-AS1, 37 LINC00337 and LNXI-ASI as a biomarker to evaluate the risk of a firefighter suffering lung 38 cancer and other cancers.

\section{Key words}

41 Competing endogenous RNAs (ceRNAs); firefighters; lung cancer; biomarker; PAHs, 42 VOCs

\section{Introduction}

In recent researches, numerous transcriptions of the human genome were documented.

Surprisingly, less than $2 \%$ of the total human genome encodes protein-coding genes, indicating that a prominent proportion of transcriptome from the human genome may the non-coding RNAs [1]. Recent reports suggest that the human transcriptome includes not only coding-RNA but about 9,000small RNAs, 10,000-32,000 long-non-coding RNAs (lncRNAs) and a cluster of pseudogenes [2,3]. Micro RNA (miRNA) are endogenous RNA transcripts

51 that regulate gene expression by binding with the specific regions of mRNA [4] and promoting their degradation [5]. Dysregulated miRNA expression may cause many different 
(lncRNA) are a cluster of RNA that can vary in length from 200 nucleotides to 1000 kilobases and have been confirmed that involve in a diverse range of biological processes from pluripotency to immune responses [8]. The best-studied example is XIST, an RNA gene that could recruit chromatin-modifying complexes to block the chromosome activate [8] and the non-coding transcriptome is often shows dysregulated in cancer [9]. As the best-known character of lncRNA as competing for endogenous RNAs (ceRNAs), the specific RNAs can impair microRNA (miRNA) activity through sequestration, thereby upregulating miRNA target gene expression [10-12]. Many studies proposed that naturally occurring coding-RNA and non-coding-RNA transcripts can act as endogenous miRNA sponges or a ceRNA [12-14].

63 With the ceRNAs communication and co-regulation, the gene which downregulated by 64 miRNA may get an increasing expression. A lot of genes with known ceRNA interactors identified so far have been implicated in human disease [1]. For example, the KLK10 which is documented to be up-regulated in ovarian cancer caused by miRNA dysregulated [15]; The hsa-miR-1260b plays an important role in renal cancer cells by interacting with some molecule in the Wnt signaling pathway [16]. The discovery of ceRNA regulation in diverse species, such as viruses, plants, mice, and human suggest that it may represent a widespread layer of gene and biological process regulation [14, 17-20]. various molecularly characterized tumor types [21], various gene expression quantification 73 and transcriptome profile is documented in the database. In recent decades, more and more 74 researches are based on the data from TCGA [22-25]. For example, researchers could 75 according to the mutation analysis, copy number analysis, mRNA or miRNA expression level 
analysis, DNA methylation analysis and signal pathway analysis to evaluate the relationship between ceRNA and cancer, even to predict the survival rate from clinical data $[22,26]$. Prediction and evaluation results of transcriptome may suggest rational advice that how to manipulate a gene that is involved in the cancer process [27]. Thus, analyzing the transcriptome from cancer patients to get some predictable results for clinical or risk evaluation, the TCGA database may a novel method.

Building fires typically involve furnishings and other items made of both natural and synthetic materials [28]. These materials may produce hundreds of combustion byproducts that usually toxic to human. The byproducts including polycyclic aromatic hydrocarbons (PAHs), acid gases, cyanide, aldehydes, hydrogen cyanide, polychlorinated biphenyls, sulfur dioxide (SO2) and halogenated compounds [29-32]. Several of these compounds are known or suspected human carcinogens and pathogeny [33-35]. Some research suggests that firefighters have increased risk for numerous types of cancer. The International Agency for Research on Cancer (IARC) reported that occupational exposure as a firefighter to be possibly carcinogenic to humans [36]. Although firefighters usually wear a self-contained breathing apparatus (SCBA) to protect them from toxic smoke, recent studies reported that firefighters may not always wear the SCBA during exterior operations and some compounds could be absorbed through skin [28, 37-39]. In recent decades, the more and more flame-proof door is used in structures to block the fire through over each room of a building.

However, the flame retardant that used in the door can produce a group of toxic compounds during a structure fire and it may have a bad influence on firefighter's health [40]. 

mRNA or the structure of chromosome that may block transcription of some gene, in the past. However, in recent years, more researchers noted that the carcinogen may dysregulate the miRNA or lncRNA first, then they induced the mRNA dysregulated [41]. For example, DDT

101 and PAHs down-regulated the miRNA hsa-miR-21, hsa-miR-221, hsa-miR-222 and hsa-miR-429 to induce the target of them that $C Y P 1 A$ and $C Y P 2 B$ up-regulated in the liver [1]

103 and they play an important role in various cancer [42]. Volatile organic compounds (VOCs)

104 could induce the miRNA that involved in the lung cancer process dysregulated $[43,44]$. Some 105 studies suggested that the alteration of lncRNA expression is correlated with polycyclic 106 aromatic hydrocarbons (PAHs) exposure [45]. For the reason above, the carcinogen from

107 Vitro may involve in the cancer process via disturbing the expression level of lncRNA and 108 miRNA. Moreover, firefighters always exposed to PAHs and VOCs may have a high risk to 109 suffer lung cancer.

110 In our study, we tested the combustion byproducts from a fire-proof door, the results 111 showed that the main components of these byproducts were SO2, polycyclic aromatic 112 hydrocarbons (PAHs), cyanide, aldehydes, polychlorinated biphenyls and halogenated 113 compounds. The analysis result from the TCGA-LUAD project was showed that in the 114 ceRNA network which was constructed by our method 17 mRNA up-regulated, 9 mRNA 115 down-regulated; 15 miRNA up-regulated, 3 miRNA down-regulated; 121 lncRNA 116 up-regulated, 20 lncRNA down-regulated. The survival curve result showed that the 117 expression level of 13 lncRNA, 3mRNA, and 4miRNA may have an impact on the survival 118 time of the cancer patients. These results provide a credible risk evaluation network for 
119 firefighters whether suffering lung cancer, and it may supply a cluster of molecular

120 biomarkers to evaluate the health status of firefighters.

121 2Method and materials

$122 \quad$ 2.1 Fire Smoke Analyzing

123 The smoke of the flame-proof door was collected by an independent intellectual property

124 system (authorizing, announcement number: CN110108546A), the sample door was flamed

125 in the combustion chamber, the smoke was collected from the window on the proof (Fig. 1A

126 and B). The collected smoke was analyzed by a multi-flue gas analyzer.

\section{2 mRNA, miRNA and lncRNA expression data}

Transcriptome profile and gene expression quantification data for 1145 lung cancer specimens were downloaded from the TCGA data portal in February 2020. The microRNA expression data for 1091 lung cancer specimens were also retrieved from the TCGA data portal. The RNA-seq data were generated by Illumina HiSeqRNASeq and HiSeqmiRNAseq platform. All the data were downloaded by a TCGA official tool with metafiles annotating each dataset. All the significance level of expression data was set at $\mathrm{P}<0.01$ and the thresholds

134 were set as $\mid \log 2$ FoldChange $\mid>2$. The differentially expressed miRNAs, mRNAs, and lncRNAs were annotated using ENSEMBL (https://www.ensembl.org/).

\section{3 ceRNAs network construction} construction, all the gene was matched with miRDB (http://mirdb.org), miRTarBase 
141 (http://www.targetscan.org/vert_72/), the different gene which could find it upstream or

142 downstream was involved in the ceRNA network [47,48]. Besides, by combining the

143 discriminatory expression profiles data, the interaction between IncRNAs and mRNAs was

144 identified. The ceRNA network of mRNA-lncRNA-miRNA was visualized with Cytoscape

$145 \quad$ v3.7.1.

$146 \quad 2.4$ Statistical Analyses

147 The heatmap, volcano plots, Venn diagram, and survival curve were computed and

148 plotted for each mRNA, miRNA, and lncRNA using R. Sequencing data were

149 log-transformed for plotting. The direct read counts and counts normalized according to

150 thousands of mRNAs, miRNAs, and lncRNAs were examined as part of our research.

$151 \quad 2.5$ Survival Analyses

152 The survival curve was analyzed from a clinical file that annotated all the status of

153 patients. Patients survival was calculated as time in months elapsed from data diagnosis until

154 data of last contact.

1552.6 Prognosis risk scoring in differentially expressed RNAs

156 Univariate Cox regression analysis was conducted where $\mathrm{P}<0.001$ was considered

157 statistically significant. The significant mRNAs in univariate Cox regression were

158 subsequently analyzed in a multivariate Cox regression proportional hazards model.

159 Furthermore, based on the median risk score, lung cancer patients were divided into

160 "high-risk" and "low-risk" groups. The risk scoring system was constructed by previous

161 research [49] and the formula as follows for predicting overall survival (OS): risk score $=\beta \mathrm{g}$

$1621 \times \operatorname{exprg} 1+\beta \mathrm{g} 2 \times \operatorname{exprg} 2+:::+\beta \mathrm{g} n \times \operatorname{exprg} \mathrm{n}$. 
164 were then performed to assess the risk scoring system with high and low scores. The survival

165 and ROC analyses were accomplished by using the R package that "survival" and "survival 166 ROC".

\section{$167 \quad 3$ Result}

$168 \quad 3.1$ Fire smoke analyses

169 The smoke of the sample door was collected for components analysis. The main

170 combustion was SO2, PAHs, cyanide, aldehydes, polychlorinated biphenyls, and halogenated

171 compounds and the concertation of each part was shown in Fig. 2.

\section{$172 \quad 3.2$ Gene expression pattern analyses and ceRNA network construction}

173 Clinical information about lung cancer patients from the TCGA database was available

174 in 1037 of 1145 cases. The total number of differently expressed mRNA was 2695 and 670 of

175 them were down-regulated, 2295 of them were up-regulated. The differently expressed

176 mRNAs are visualized in the heatmap and a volcano plot (Fig. 3A and Fig. 4A). The total

177 number of differently expressed miRNA was 134, and 16 of them were down-regulated, 118

178 was up-regulated. The differently expressed miRNAs are visualized in the heatmap and a

179 volcano plot (Fig. 3B and Fig. 4B). The total number of differently expressed lncRNA was

1801915 , and 247 of them were down-regulated, 1668 was up-regulated. The differently

181 expressed lncRNAs are visualized in the heatmap and a volcano plot (Fig. 3C and Fig. 4C).

182 All the RNAs that differently expressed were listed in Table1-3.

183 According to our differential expression analysis, the ceRNA network was constructed.

184 After ceRNA network construction, 26 different expressed mRNA was the target of different 
expressed lncRNA and miRNA (Fig. 5A). All the relationship of miRNA-mRNA and lncRNA-miRNA was listed in Table 4-5.

The ceRNA network was showed that the key target of lncRNA was hsa-hsa-miR-210, hsa-miR-96, hsa-miR-137, hsa-miR-183, hsa-miR-503, hsa-miR-372, hsa-miR-205, hsa-miR-144, hsa-miR-143, hsa-miR-182, hsa-miR-373, hsa-miR-215, hsa-miR-192, hsa-miR-31, hsa-miR-122, hsa-miR-206, hsa-miR-301b and hsa-miR-383 (Fig. 5A and B).

To understand the key molecule in the ceRNA network clearly, we were constructed a miRNA-mRNA, IncRNA-miRNA, and miRNA-IncRNA-mRNA network (Fig. 5A-C). The result of the miRNA-mRNA network showed that hsa-miR-373, hsa-miR-372 and hsa-miR-144 may play an important role in the ceRNA-network (Fig. 5B). The target gene of the miRNA is involved in energy metabolism and cancer development processes, such as TMEM100, ATAD2, PFKP and KPNA2. The KPNA2 may play an adaptor molecule between $h s a-m i R-373$ and $h s a-m i R-144$, the expression level of it may co-regulated by $h s a-m i R-373$ and $h s a-m i R-144$ (Fig. 5B). In the lncRNA-miRNA network, numerous lncRNA was involved in the network that plays an important role in tumor development and migration, about 120 lncRNAs was up-regulated and 20 lncRNAs was down-regulated (Fig. 5C).

\subsection{Survival Analyses}

To perform the survival curve, we were analyzed the lncRNA, miRNA and mRNA that expression level with a significantly different $(\mathrm{P}<0.01)$. The results showed that the expression level of 13 lncRNAs, 3 mRNAs and 4 miRNAs may have an impact on the patient survival time (Fig. 6). Interestingly, most of these genes whatever miRNA, mRNA and 
lncRNA, have no significant difference in the first 3 years, and after 5 years the different expression level showed a more significant impact on survival time.

According to the results of the ceRNA network and survival curve of lung cancer

209 patients indicated that mRNA CCNB1 (cyclin B1) was up-regulated by miRNA hsa-miR-183

210 and the hsa-miR-183 was up-regulated by LINC00392, AL161908.1, AL139385.1,

211 AL513123.1, LSAMP-AS1 and TTTY16 (Fig. 5A). The mRNA of COL1A1 (Collagen 1A1)

212 was up-regulated by $h s a-m i R-143$, and miRNA $h s a-m i R-143$ was down-regulated by lncRNA

213 LPP-AS1, AL391152.1 and LINC00519 (Fig. 5A). The mRNA of PFKP (phosphofructokinase)

214 was up-regulated by miRNA $h s a-m i R-372$ and $h s a-m i R-372$, and they were co-regulated by

215 lncRNA LINC00337, LNXI-AS1 and MUC2 (Fig. 5A and C). The miRNA all above was also

216 co-regulated by numerous IncRNA that not mentioned in the article and showed in the

217 ceRNA network (Fig. 5A). However, some lncRNAs such as AC080129.1, AL163952.1 and

218 MIR31-HG, showed a relationship with survival time, but the downstream molecule of them

219 have no significant relationship with survival time.

\subsection{Prognostic risk score based on differentially expressed mRNAs}

221 A total of 3365 differently expressed mRNAs, we found 50 mRNAs to be significantly

222 associated with survival using univariate Cox regression, the significant genes demonstrated

223 in the univariate Cox regression model was listed in Table 6. According to the multivariate

224 Cox regression analysis, 18 mRNA expression profiles were identified as coupled to overall

225 survival and included in the overall survival prediction model (Fig. 7A). The mRNA

226 expression profiles for prediction of overall survival in lung cancer by multivariate Cox

227 regression were listed in Table 7 (Events: 395, N=999, $\mathrm{p}=2.2 \mathrm{e}-16$ ). On the basis of the 
overall survival prediction model, a prognostic risk model was constructed where the

229 high-risk group was significantly associated with lower overall survival $(\mathrm{P}<0.01)$ (Fig. 7B).

230 The discriminative evaluation of the risk scoring system was performed with ROC-curve

231 analysis were found an AUC (Area Under Curve) $=0.722$ (Fig 7B and C). These results

232 showed that the patients could live longer in the condition to do cancer testing and treatment

233 earlier.

234 Thus, there is more benefit to detect lung cancer biomarkers for firefighters.

\section{Discussion}

236 In our study, the major chemical that produced by a flame-proof door when it is on fire

237 was PAHs, VOCs, SO2 and cyanide, they were well-known carcinogens for a long time. All

238 the combustion byproducts in our study were researched in many other kinds of research

239 [50-52]. Research showed that in hundreds of lung cancer cases there was a clear trend of

240 increasing risk of lung cancer with increasing cumulative exposure to PAHs [53]. VOCs

241 could produce oxidative stress with DNA damage and increasing the endogenous catechol

242 levels by catechol-O-methyl transferase (COMT) inhibition [54]. For firefighters, they have

243 more chance to breathe or face the air with high concentration VOCs, and researches showed

244 that VOCs could absorb via skin directly [55-57]. Cyanide and SO2 were typically toxic for

245 human health, they not only induce oxidative damage in many organisms simultaneously but

246 the toxic effects permanently $[58,59]$. The $\mathrm{SO} 2$ and its derivatives SO32- could promote

247 cancer development and metastasis through integrin $\alpha v \beta 3$ activation or other molecules [60,

248 61]. 
About 13 lncRNAs, 3 mRNAs and 4 miRNAs were involved in the ceRNA network of lung cancer process and have a significant impact on survival time. These RNA molecules

251 were played an important role in lung cancer development such as initiation, invasion and 252 migration [62, 63]. The different expression levels of COL1A1, CCNB1 and PFKP have an 253 influence on survival time in our research. Researches showed that the expression level of 254 COL1A1 and CCNB1 can dysregulate by PAHs and VOCs [64-67]. However, there has no 255 evidence to prove that the VOCs or PAHs could impact the expression level of PFKP directly. 256 More researches on PFKP was about how it works in the metabolism process of tumor cell [1, 257 2].

The down/overexpression of protein-coding genes such as COL1A1, PTK6, elongation factor 1 gamma in tumor tissues may provide preoperative useful information for predicting the development and aggressiveness of tumors. Besides, some studies showed that hsa-miRNA-211, hsa-miRNA-143, hsa-miRNA-183, and lncRNA CASC9, HOTAIR, POU3F3 contributed to the development of cancer via a variety of mechanisms [70]. The relationship between COL1Al and hsa-miR-143, hsa-miR-183 was proofed in our ceRNA network (Fig. 5A). The $h s a-m i R-143$ work as a tumor inhibitor to block the vascular development from the tumor [71]. The smoke of cigarettes was confirmed that containing PAHs and VOCs, the 266 concentration of them from a cigarette lower than a construction fire could damage the human 267 health and increase the risk for suffering a lung cancer [72, 73]. Papers on the hsa-miR-143 268 suggested that cigarette exposure could down-regulate the expression level of hsa-miR-143 269 and causes a variety of cancers including lung cancer [74]. The lncRNA UCA1 negatively 270 regulated has-miR-143 expression in a dose-dependent manner in various cancer cells [75, 
271 76]. In our research, the lncRNA UCAl not only as a regulator for hsa-miR-143 but other 272 miRNAs (Fig. 5A). However, how it works in lung cancer cell need further research. Thus, 273 hsa-miR-143 may up-regulate the expression level of COL1Al to induce lung cancer by 274 down-regulating the expression level of itself in our study. The expression level of 275 hsa-miR-143 was down-regulated by UCAl and co-regulated by other lncRNAs.

277 ensuring completion of M phase [77]. Research on CCNBI was showed that it associated with 278 lung cancer and could promote $N S C L C$ (non-small cell lung cancer) cell proliferation and cell 279 cycle progression [78]. Silencing lncRNA CRNDE inhibited cell proliferation, migration and 280 invasion, restricted solid tumor growth and promoted cell apoptosis [79]. Moreover, 281 hsa-miR-183 silencing could inverse the antitumor function of CRNDE inhibition and 282 partially eliminated the attenuated expression of CCNB1 induced by silencing CRNDE, 283 indicating that $C R N D E$ could positively regulate CCNB1 expression by sponging $284 h s a-m i R-183[79]$. The function of $h s a-m i R-183$ to regulate CCNBI was showed in our study, 285 however, the $h s a-m i R-144$ also showed $C C N B 1$ regulating function. Researchers showed that 286 hsa-miR-144 directly targeted CCNBI and inhibited CCNBI expression [80]. For all the 287 reasons above, our study suggested that CCBN1 was co-regulated by hsa-miR-144 and 288 hsa-miR-183. LSAMP-AS1 binds to hsa-miR-183 to suppress the cancer progression by 289 up-regulating the tumor suppressor DCN (decorin) [81]. However, hsa-miR-183 was 290 up-regulated and LSAMP-ASI was up-regulated too, thus, the lncRNA LSAMP-ASI may not 291 the key role to $h s a-m i R-183$ regulation. The smoke that contains PAHs and VOCs could alter 292 the normal expression pattern of hsa-miR-183 and involve in early-stage non-small cell lung 
cancer [82, 83]. The IncRNA TTTY16 was down-regulated and associated with

294 hsa-miR-183-CCBN1 signaling in our ceRNA network. Recent research also showed that

295 TTTY16 associated with hsa-miR-183[84]. However, there is no enough evidence to prove

296 that TTTY16 up-regulates CCBN1 by up-regulates $h s a-m i R-183$. According to our study, we

297 predicted that TTTY16 may play an important role in hsa-miR-144/hsa-miR-183-CCBN1

298 signaling in lung cancer.

299 PFKP plays an important metabolic role in the process of tumor development, migration

300 and invasion. Low expressed PFKP could promote autophagy of tumor cells and

301 overexpressed it could enhance the invasion and metastasis ability of tumor cells $[68,69,85]$.

302 The microRNA $h s a-m i R-372 / 372$ was suggested that working as a competing endogenous to

$303 \quad P F K P$ in prostate cancer [86]. Moreover, researchers reported that not all the ceRNA have a

304 negative relation between each other and the cross-link of them may more difficult than what

305 we have known already [10] and that may the reason for the expression level of PFKP,

$306 h s a-m i R-372$ and $h s a-m i R-373$ was all up-regulated in our study. A lot of studies were

307 reported that $h s a-m i R-372 / 373$ was regulated by LINC00337 but the mechanism of that was

308 not clear [87-89]. The lncRNA LNX1-AS1 was a new role that found have a relation with

309 hsa-miR-372/373, it may a novel molecule for ceRNA researching in lung cancer. We can

310 confirm that PFKP and miRNA which it associates was played an important role in lung

311 cancer from our study.

312 We have identified a large number of differentially expressed mRNAs, IncRNAs, and

313 miRNAs in lung cancer which were strongly associated with PAHs and VOCs. Many of these

314 RNAs have not been reported in the current literature as related to lung cancer and represent 
novel and promising future targets. However, larger cohorts of patients and future mechanistic studies are necessary to validate our results and investigate their functional roles

317 in lung cancer for firefighters. Thus, the mRNA expression level of COL1A1, CCBN1 and PFKP; the miRNA expression level of hsa-miR-143, hsa-miR-183, hsa-miR-144, hsa-miR-372 and hsa-miR-373; the IncRNA expression level of UCA1, TTTY16, LSAMP-AS1, LINC00337 and LNX1-AS1

321 may recommend as a bio-mark to evaluate the risk of a firefighter suffering lung cancer and 322 other cancers. The ceRNA network showed in our study should be a reference for lung cancer 323 evaluation.

\section{Declarations}

325 5.1 Ethics approval and consent to participate

326 All the experiments were supervised and approved by the ethics committee of Tianjin Fire 327 Research Institute.

\section{$328 \quad 5.2$ Consent for publication}

329 All the authors in this research have read the final version of the manuscript.

$330 \quad 5.3$ Availability of data and materials

331 All of the transcriptome data were obtained from TCGA database and the code for R and Perl

332 could obtain from the corresponding author by email Binbaicom@163.com.

3335.4 Competing interests

334 All authors have no potential conflicts of interest.

\section{$335 \quad 5.5$ Funding}

336 This research was supported by Tianjin Fire Research Institute of MEM.

337 5.6 Author's contribution

338 Bin Bai: Conceptualization, Methodology, Writing - review \& editing. Qinghao Meng:

339 Software, Data curation, Writing - original draft. 
$341 \quad$ Not applicable.

348 1. Tay Y, Rinn J, Pandolfi PP: The multilayered complexity of ceRNA crosstalk and competition. Nature, 505(7483):344-352.

2. Volders P-J, Helsens K, Wang X, Menten B, Martens L, Gevaert K, Vandesompele J, Mestdagh P: LNCipedia: a database for annotated human IncRNA transcript sequences and structures. Nucleic Acids Research, 41(D1):D246-D251.

3. Dunham I, Birney E, Lajoie BR, Sanyal A, Dong X, Greven M, Lin X, Wang J, Whitfield TW, Zhuang J: An integrated encyclopedia of DNA elements in the human genome. 2012.

356 4. Wu L, Belasco JG: Let me count the ways: mechanisms of gene regulation by miRNAs and siRNAs. Molecular cel/2008, 29(1):1-7.

5. Eder M, Scherr M: MicroRNA and Lung Cancer. New England Journal of Medicine, 352(23):2446-2448.

360 6. Zhang L, Huang J, Yang N, Greshock J, Megraw M, Giannakakis A, Liang S, Naylor T, 361 Barchetti A, Ward M: microRNAs exhibit high frequency genomic alterations in human cancer. Proceedings of the National Academy of Sciences of the United States of 
364 7. Creighton CJ, Fountain MD, Yu Z, Nagaraja AK, Zhu H, Khan M, Olokpa E, Zariff A, 365 Gunaratne $\mathrm{PH}$, Matzuk MM: Molecular profiling uncovers a p53-associated role for microRNA-31 in inhibiting the proliferation of serous ovarian carcinomas and other

8. Nagano T, Fraser P: No-nonsense functions for long noncoding RNAs. Cell 2011,

9. Gutschner T, Diederichs S: The hallmarks of cancer: a long non-coding RNA point of view. RNA biology 2012, 9(6):703-719.

10. Thomson DW, Dinger ME: Endogenous microRNA sponges: evidence and controversy. Nature Reviews Genetics 2016, 17(5):272.

374 11. Ebert MS, Sharp PA: Emerging roles for natural microRNA sponges. Current Biology 2010, 20(19):R858-R861.

376 12. Seitz H: Redefining microRNA targets. Current biology 2009, 19(10):870-873.

377 13. Salmena L, Poliseno L, Tay Y, Kats L, Pandolfi PP: A ceRNA Hypothesis: The Rosetta Stone of a Hidden RNA Language? Cell, 146(3):0-358.

379 14. Franco-Zorrilla JM, Valli A, Todesco M, Mateos I, Puga MI, Rubio-Somoza I, Leyva A, 380 Weigel D, García JA, Paz-Ares J: Target mimicry provides a new mechanism for regulation of microRNA activity. 39(8):1033-1037.

382 15. White NMA, Chow T-FF, Mejia-Guerrero S, Diamandis M, Rofael Y, Faragalla H, Mankaruous M, Gabril M, Girgis A, Yousef GM: Three dysregulated miRNAs control kallikrein 10 expression and cell proliferation in ovarian cancer. 102(8):1244-1253. 
385 16. Hirata H, Ueno K, Nakajima K, Tabatabai ZL, Hinoda Y, Ishii N, Dahiya R: Genistein 386 downregulates onco-miR-1260b and inhibits Wnt-signalling in renal cancer cells. 387 British Journal of Cancer, 108(10):2070-2078.

388 17. Cazalla D, Yario T, Steitz JA: Down-Regulation of a Host MicroRNA by a Herpesvirus 389 saimiri Noncoding RNA. Science, 328(5985):1563-1566.

390 18. Poliseno L, Salmena L, Zhang J, Carver B, Haveman WJ, Pandolfi PP: A 391 coding-independent function of gene and pseudogene mRNAs regulates tumour $392 \quad$ biology. Nature, 465(7301):1033-1038.

393 19. Tay Y, Kats L, Salmena L, Weiss D, Tan SM, Ala U, Karreth F, Poliseno L, Provero P, 394 Di?Cunto F: Coding-Independent Regulation of the Tumor Suppressor PTEN by 395 Competing Endogenous mRNAs. 147(2):0-357.

396 20. Karreth FA, Tay Y, Perna D, Ala U, Tan SM, Rust AG, DeNicola G, Webster KA, 397 Weiss D, Perez-Mancera PA: In?Vivo Identification of Tumor- Suppressive PTEN 398 ceRNAs in an Oncogenic BRAF-Induced Mouse Model of Melanoma. 2011.

399 21. Bakas S, Akbari H, Sotiras A, Bilello M, Rozycki M, Kirby JS, Freymann JB, Farahani 400 K, Davatzikos C: Advancing The Cancer Genome Atlas glioma MRI collections with 401 expert segmentation labels and radiomic features. Scientific Data, 4:170117.

402 22. Network, Research TCGA: Integrated genomic analyses of ovarian carcinoma. Nature, 403 474(7353):p.609-615.

404 23. Sinha S, Mitchell KA, Zingone A, Bowman E, Sinha N, Schäffer AA, Lee JS, Ruppin E, 405 Ryan BM: Higher prevalence of homologous recombination deficiency in tumors from 406 African Americans versus European Americans. Nature Cancer 2020, 1(1):112-121. 
407 24. Chen F, Chandrashekar DS, Varambally S, Creighton CJ: Pan-cancer molecular 408 subtypes revealed by mass-spectrometry-based proteomic characterization of more than 500 human cancers. Nature Communications 2019, 10(1):1-15.

25. Bhattacharya A, Bense RD, Urzúa-Traslaviña CG, de Vries EG, van Vugt MA, Fehrmann RS: Transcriptional effects of copy number alterations in a large set of human cancers. Nature Communications 2020, 11(1):1-12.

413 26. Mitra R, Adams CM, Jiang W, Greenawalt E, Eischen CM: Pan-cancer analysis

27. Milanez-Almeida P, Martins AJ, Germain RN, Tsang JS: Cancer prognosis with shallow tumor RNA sequencing. Nature Medicine 2020:1-5.

28. Fent KW, Toennis C, Sammons D, Robertson S, Bertke S, Calafat AM, Pleil JD, Wallace MAG, Kerber S, Smith D: Firefighters' absorption of PAHs and VOCs during controlled residential fires by job assignment and fire attack tactic. Journal of exposure science \& environmental epidemiology 2019:1-12.

29. Jankovic J, Jones W, Burkhart J, Noonan G: Environmental study of firefighters. The Annals of occupational hygiene 1991, 35(6):581-602.

30. Fabian TZ, Borgerson JL, Gandhi PD, Baxter CS, Ross CS, Lockey JE, Dalton JM: Characterization of firefighter smoke exposure. Fire Technology 2014, 50(4):993-1019.

427 31. Austin C, Wang D, Ecobichon DJ, Dussault G: Characterization of volatile organic 428 compounds in smoke at municipal structural fires. Journal of Toxicology and 
430 32. Fent KW, Evans DE, Babik K, Striley C, Bertke S, Kerber S, Smith D, Horn GP: Airborne contaminants during controlled residential fires. Journal of occupational and

433 33. Wu M-T, Lin P-C, Pan C-H, Peng C-Y: Risk assessment of personal exposure to polycyclic aromatic hydrocarbons and aldehydes in three commercial cooking

34. Donat-Vargas C, Åkesson A, Berglund M, Glynn A, Wolk A, Kippler M: Dietary exposure to polychlorinated biphenyls and risk of breast, endometrial and ovarian cancer in a prospective cohort. British journal of cancer 2016, 115(9):1113-1121.

35. Martinez AF, McCachren SS, Lee M, Murphy HA, Zhu C, Crouch BT, Martin HL,

36. Humans IWGotEoCRt: Painting, firefighting, and shiftwork. IARC monographs on the evaluation of carcinogenic risks to humans / World Health Organization, International Agency for Research on Cancer 2010, 98(3):9-764.

37. Keir JLA, Akhtar US, Matschke DMJ, Kirkham TL, Chan HM, Ayotte P, White PA, Blais JM: Elevated Exposures to Polycyclic Aromatic Hydrocarbons and Other Organic Mutagens in Ottawa Firefighters Participating in Emergency, On-Shift Fire Suppression. Environmental Science \& Technology.acs.est.7b02850.

450 38. Wingfors, H?kan, Nyholm, Jenny, Rattfelt, Magnusson, Roger, Wijkmark, Cecilia, 

by Skin Deposition and Urinary Biomarkers.

39. M. VJG, M. B-BM, J. HPM, J. JF: REDUCTION OF URINARY 1-HYDROXYPYRENE EXCRETION IN COKE-OVEN WORKERS EXPOSED TO POLYCYCLIC AROMATIC HYDROCARBONS DUE TO IMPROVED HYGIENIC SKIN PROTECTIVE MEASURES. Annals of Occupational Hygiene 1994(3):3.

40. Lazar ST, Kolibaba TJ, Grunlan JC: Flame-retardant surface treatments. Nature Reviews Materials 2020.

459 41. Chanyshev M, Kosorotikov N, Titov S, Kolesnikov N, Gulyaeva L: Expression of microRNAs, CYP1A1 and CYP2B1 in the livers and ovaries of female rats treated with DDT and PAHs. Life sciences 2014, 103(2):95-100.

42. Lozza L, Moura-Alves P, Domaszewska T, Crespo CL, Streata I, Kreuchwig A, Puyskens A, Bechtle M, Klemm M, Zedler U: The Henna pigment Lawsone activates the Aryl Hydrocarbon Receptor and impacts skin homeostasis. Scientific reports 2019, $9(1): 1-21$

43. Wang F, Li C, Liu W, Jin Y: Modulation of microRNA expression by volatile organic compounds in mouse lung. Environmental Toxicology 2014, 29(6):679-689.

44. Izzotti A, Larghero P, Cartiglia C, Longobardi M, Pfeffer U, Steele VE, De Flora S: Modulation of microRNA expression by budesonide, phenethyl isothiocyanate and cigarette smoke in mouse liver and lung. Carcinogenesis, 31(5):p.894-901.

471 45. Specific long non-coding RNAs response to occupational PAHs exposure in coke oven workers. Toxicology Reports, 3:S2214750015301001. 
473 46. Salmena L, Poliseno L, Tay Y, Kats L, Pandolfi P: A ceRNA hypothesis: the Rosetta Stone of a hidden RNA language? Cell 2011; 146: 353-358. Cell Physiol Biochem 2018, 51:886-896.

47. Huang H-Y, Lin Y-C-D, Li J, Huang K-Y, Shrestha S, Hong H-C, Tang Y, Chen Y-G, Jin C-N, Yu Y: miRTarBase 2020: updates to the experimentally validated microRNAtarget interaction database. Nucleic acids research 2020, 48(D1):D148-D154. microRNA targets predicts functional non-conserved and non-canonical sites. 11(8). survival prediction of patients with hepatocellular carcinoma. Peerj 2017, 5(7). A, Sram R, Brdicka R: Effect of maternal tobacco smoke exposure on the placental

51. Helen GS, Benowitz NL, Ko J, Jacob P, Gregorich SE, Pérez-Stable EJ, Murphy SE, transcriptome. Placenta 2010, 31(3):186-191. elucidating of an unusual growth mechanism for polycyclic aromatic hydrocarbons in

493 53. Armstrong, Gibbs: Exposure-response relationship between lung cancer and polycyclic aromatic hydrocarbons (PAHs). 
495 54. Recio-Vega R, Mendez-Henandez A, Gabriel APy, Jacobo-Avila A, Portales496 Castanedo A, Hernandez-Gonzalez S, Gallegos-Arreola MP, Ocampo-Gomez G: 497 Potentially estrogenic polychlorinated biphenyls congeners serum levels and its 498 relation with lung cancer. Journal of applied toxicology 2013, 33(9):906-914.

$499 \quad 55 . \quad$ Agency UEP: Dermal exposure assessment: Principles and applications. In.: Office of 500

501 56. Thrall KD, Poet TS, Corley RA, Tanojo H, Edwards JA, Weitz KK, Hui X, Maibach HI, $502 \quad$ Wester RC: A real-time in-vivo method for studying the percutaneous absorption of 503

57. Wester RC, Maibach HI: Benzene percutaneous absorption: dermal exposure relative 506

508 58. Petkovic AM, Jakovljevic VL, Bradic JV, Jeremic JN, Jeremic NS, Nikolic Turnic TR, 509

515 60. Wang Y, Yue S, Zheng B, Hao Z, Chen J: A general method for evaluating the effects 516 of air pollutants on lung cancer prevalence. Journal of the Air \& Waste Management 
518 61. Ji P, Li Z, Dong J, Yi H: SO2 derivatives and as co-exposure promote liver cancer metastasis through integrin $\alpha v \beta 3$ activation. Ecotoxicology and environmental safety

62. Lee Y-C, Kurtova AV, Xiao J, Nikolos F, Hayashi K, Tramel Z, Jain A, Chen F, Chokshi M, Lee C: Collagen-rich airway smooth muscle cells are a metastatic niche for tumor colonization in the lung. Nature communications 2019, 10(1):1-16.

524 63. Oleksiewicz U, Liloglou T, Tasopoulou K-M, Daskoulidou N, Gosney JR, Field JK, Xinarianos G: COL1A1, PRPF40A, and UCP2 correlate with hypoxia markers in non-small cell lung cancer. J Cancer Res Clin Oncol, 143(7):1133-1141.

527 64. Tabuso M, Adya R, Gopalakrishnan K, James S, White A, Fisk A, Dimitri F, Butler J, 528 Christian M, Arasaradnam RP: OWE-23 Versatile role of secreted frizzled related protein 2 (SFRP2) in colon cancer: Potential stromal target. In.: BMJ Publishing Group; 2019.

531 65. Wu M, Liang G, Duan H, Yang X, Qin G, Sang N: Synergistic effects of sulfur dioxide and polycyclic aromatic hydrocarbons on pulmonary pro-fibrosis via mir-30c-1-3p/transforming growth factor $\beta$ type II receptor axis. Chemosphere 2019, 219:268-276.

535 66. Zhou Y, Gan F, Zhang Y, He X, Shen C, Qiu H, Liu P: Selective Killing of Cancer Cells 536 by Nonplanar Aromatic Hydrocarbon-Induced DNA Damage. Advanced Science 2019, 537 6(21):1901341.

538 67. Model CCNM: Tinzaparin Tedavisinin Oral Yassı Hücreli Karsinoma Çıplak Fare 

6(3):131-135.

541 68. Kim NH, Cha YH, Lee J, Lee S-H, Yang JH, Yun JS, Cho ES, Zhang X, Nam M, Kim N: Snail reprograms glucose metabolism by repressing phosphofructokinase PFKP allowing cancer cell survival under metabolic stress. Nature communications 2017, 8(1):1-12.

69. Peng M, Yang D, Hou Y, Liu S, Zhao M, Qin Y, Chen R, Teng Y, Liu M: Intracellular citrate accumulation by oxidized ATM-mediated metabolism reprogramming via PFKP

70. Yue Y, Song M, Qiao Y, Li P, Yuan Y, Lian J, Wang S, Zhang Y: Gene function and CS enhances hypoxic breast cancer cell invasion and metastasis. Cell death \&

71. Dimitrova N, Gocheva V, Bhutkar A, Resnick R, Jong RM, Miller KM, Bendor J, Jacks $\mathrm{T}$ : Stromal expression of miR-143/145 promotes neoangiogenesis in lung cancer

72. Weinstein J, Thompson L, Asteria-Peñaloza R, Diaz-Artiga A, Davila G, Benowitz N: Urinary biomarkers of exposure to polycyclic aromatic hydrocarbons and volatile organic compounds among rural Guatemalan women using biomass for cooking. In:

559 73. Weinstein JR, Asteria-Peñaloza R, Diaz-Artiga A, Davila G, Hammond SK, Ryde IT, 

cooking and heating with solid fuels. International journal of hygiene and environmental health 2017, 220(4):726-735.

564 74. Boubaker NS, Spagnuolo M, Trabelsi N, Said R, Gurtner A, Regazzo G, Ayed H, Blel A, Karray $O$, Saadi A: miR-143 expression profiles in urinary bladder cancer: correlation with clinical and epidemiological parameters. Molecular Biology Reports 2020, 47(2):1283-1292.

75. Luo J, Chen J, Li H, Yang Y, Yun H, Yang S, Mao X: LncRNA UCA1 promotes the invasion and EMT of bladder cancer cells by regulating the miR-143/HMGB1 pathway. Oncology letters 2017, 14(5):5556-5562.

76. Li Z, Niu H, Qin Q, Yang S, Wang Q, Yu C, Wei Z, Jin Z, Wang X, Yang A: IncRNA UCA1 mediates resistance to cisplatin by regulating the miR-143/FOSL2-signaling pathway in ovarian cancer. Molecular Therapy-Nucleic Acids 2019, 17:92-101.

77. Draviam VM, Orrechia S, Lowe M, Pardi R, Pines J: The Localization of Human Cyclins B1 and B2 Determines Cdk1 Substrate Specificity and Neither Enzyme Requires Mek to Disassemble the Golgi Apparatus. Journal of Cell Biology, 152(5):945-958.

78. Wang F, Chen X, Yu X, Lin Q: Degradation of CCNB1 mediated by APC11 through UBA52 ubiquitination promotes cell cycle progression and proliferation of non-small cell lung cancer cells. American Journal of Translational Research 2019, 11(11):7166.

581 79. Bai X, Wang W, Zhao P, Wen J, Guo X, Shen T, Shen J, Yang X: LncRNA CRNDE acts as an oncogene in cervical cancer through sponging miR-183 to regulate CCNB1 
expression. Carcinogenesis 2019.

584 80. Gu J, Liu X, Li J, He Y: MicroRNA-144 inhibits cell proliferation, migration and invasion in human hepatocellular carcinoma by targeting CCNB1. Cancer cell international

81. Hua X, Liu Z, Zhou M, Tian Y, Zhao P-P, Pan W-H, Li C-X, Huang X-X, Liao Z-X, Xian Q: LSAMP-AS1 binds to microRNA-183-5p to suppress the progression of prostate cancer by up-regulating the tumor suppressor DCN. EBioMedicine 2019, 50:178-190.

82. Zhu W, Zhou K, Zha Y, Chen D, He J, Ma H, Liu X, Le H, Zhang Y: Diagnostic value of serum miR-182, miR-183, miR-210, and miR-126 levels in patients with early-stage

83. Khan AA, Advani J, Patel K, Nanjappa V, Datta KK, Solanki HS, Kumar P, Mathur PP, non-small cell lung cancer. PloS one 2016, 11(4).

84. $\mathrm{Hu} \mathrm{J}, \mathrm{Xu} \mathrm{L}$, Shou T, Chen Q: Systematic analysis identifies three-IncRNA signature as a potentially prognostic biomarker for lung squamous cell carcinoma using bioinformatics strategy. Translational lung cancer research 2019, 8(5):614.

600 85. Chen G, Liu H, Zhang Y, Liang J, Zhu Y, Zhang M, Yu D, Wang C, Hou J: Silencing Nair B, Keshava Prasad TS: Chronic exposure to cigarette smoke and chewing tobacco alters expression of microRNAs in esophageal epithelial cells. Microrna 2018, $7(1): 28-37$.

85. PFKP inhibits starvation-induced autophagy, glycolysis, and epithelial mesenchymal transition in oral squamous cell carcinoma. Experimental cell research 2018,

604 86. Xu N, Wu Y-P, Yin H-B, Xue X-Y, Gou X: Molecular network-based identification of 

competing endogenous RNAs and mRNA signatures that predict survival in prostate cancer. Journal of translational medicine 2018, 16(1):274.

87. Xu Z, Wang C, Xiang X, Li J, Huang J: Characterization of mRNA expression and endogenous RNA profiles in bladder cancer based on the cancer genome atlas (TCGA) database. Medical science monitor: international medical journal of experimental and clinical research 2019, 25:3041.

611 88. Yu Y, Chen $\mathrm{X}$, Cang S: Cancer-related long noncoding RNAs show aberrant expression profiles and competing endogenous RNA potential in esophageal adenocarcinoma. Oncology letters 2019, 18(5):4798-4808.

614 89. Chen L-P, Wang H, Zhang Y, Chen Q-X, Lin T-S, Liu Z-Q, Zhou Y-Y: Robust analysis of novel mRNA-IncRNA cross talk based on ceRNA hypothesis uncovers carcinogenic mechanism and promotes diagnostic accuracy in esophageal cancer. 
662 Fig. 1. The test equipment system of smoke. (A) The sketch map of the equipment 663 system. The combustion chamber was marked by " 1 ". The smoke collecting window 664 was marker by “2”. (B) The practicality picture of the system. The smoke collecting 665 window was marker by "a". The smoke collecting window was marker by "b".

666 Fig. 2. The toxic smoke concentration of the door-flame experiment. The number 667 on the column marked the arithmetic mean concentration of the smoke and bar 668 indicated the mean \pm SD.

669 Fig. 3. The heatmap of the differently expressed RNAs. (A) The heatmap of

670 differently expressed mRNA. The green box showed mRNA was down-regulated and 671 red box showed mRNA up-regulated. (B) The heatmap of differently expressed 672 miRNA. The green box showed miRNA was down-regulated and red box showed 
673 miRNA up-regulated. (C) The heatmap of differently expressed lncRNA. The green

674 box showed lncRNA was down-regulated and red box showed lncRNA up-regulated.

675 Fig. 4. Differentially expressed RNAs in lung cancer are visualized by volcano

676 plots. The red dots show upregulated genes while the green dots show downregulated 677 genes. (A) Differentially expressed mRNAs in lung cancer. (B) Differentially 678 expressed miRNAs in lung cancer. (C) Differentially expressed lncRNAs in lung 679 cancer.

680 Fig. 5. The ceRNA network of lung cancer. mRNA was in rounded rectangle, 681 miRNA was in round, lncRNA was in diamond. The blue show downregulated gene 682 while red show upregulated gene. (A) ceRNA network that involve mRNA, miRNA 683 and lncRNA. (B) The RNAs network between miRNA and mRNA. (C) The RNAs 684 network between miRNA and lncRNA.

685 Fig. 6. The Kaplan-Meier plots of differentially expressed RNAs in the ceRNA 686 network which are also related to high-grade, stages, and overall survival 687 (P<0.01). (A) The survival curve of mRNAs. (B) The survival curve of miRNAs. (C) 688 The survival curve of lncRNAs.
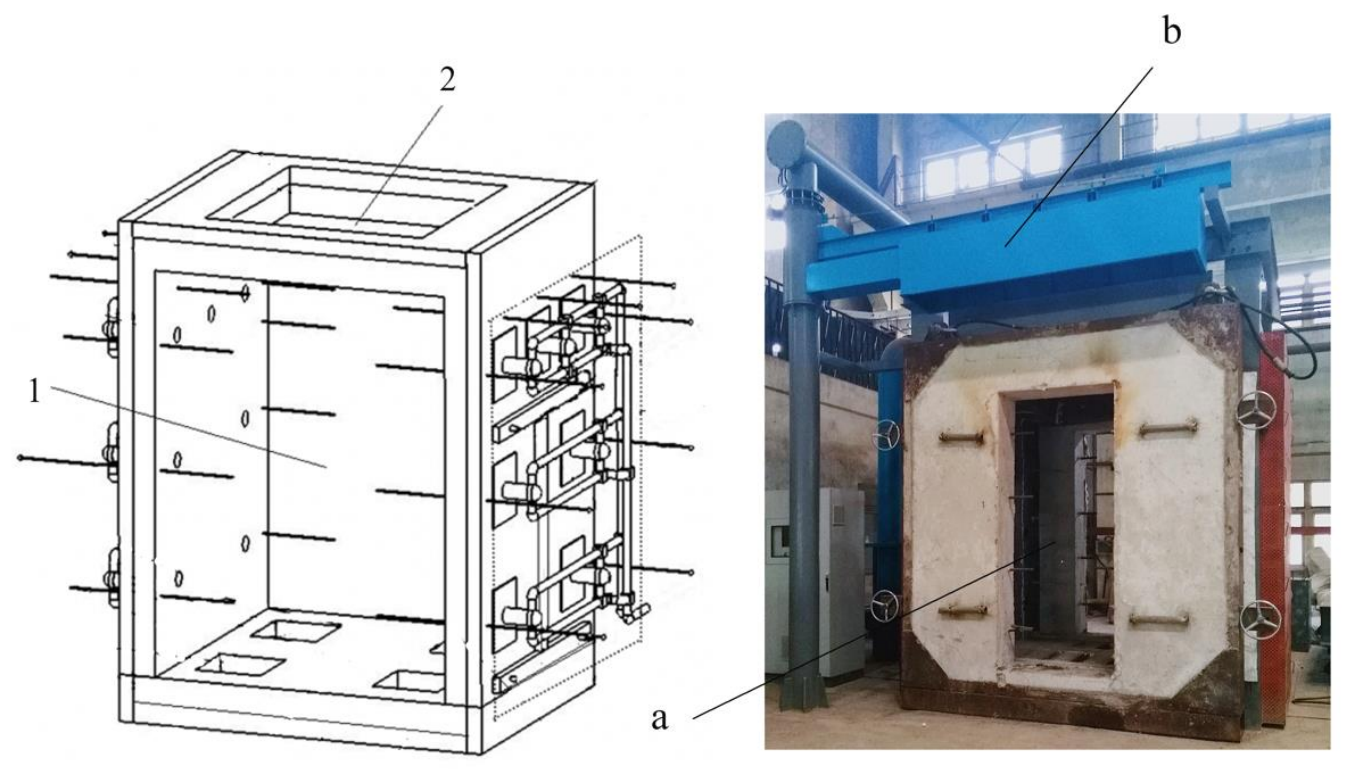
695

696

697

698

699

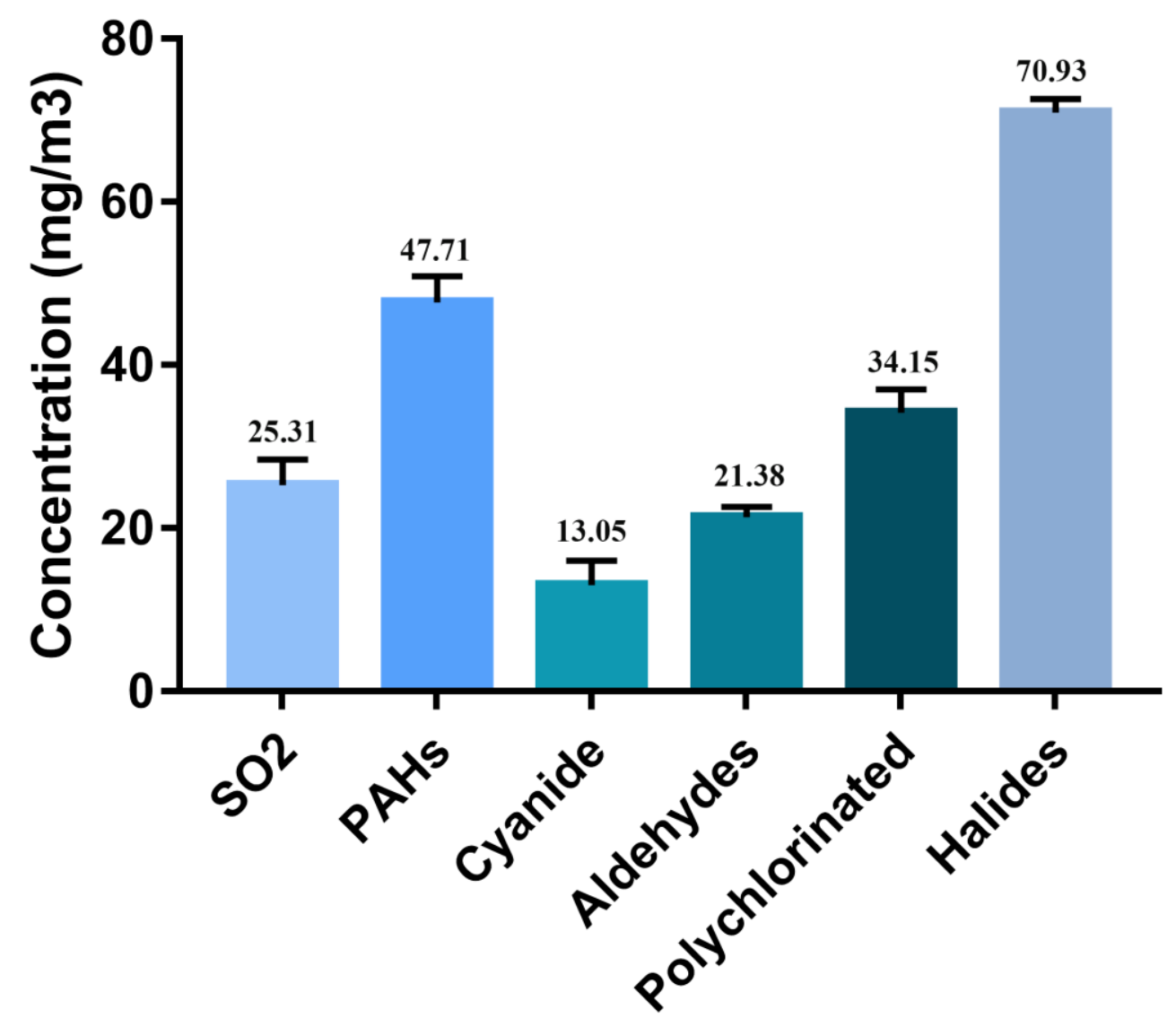

Fig. 2.

A
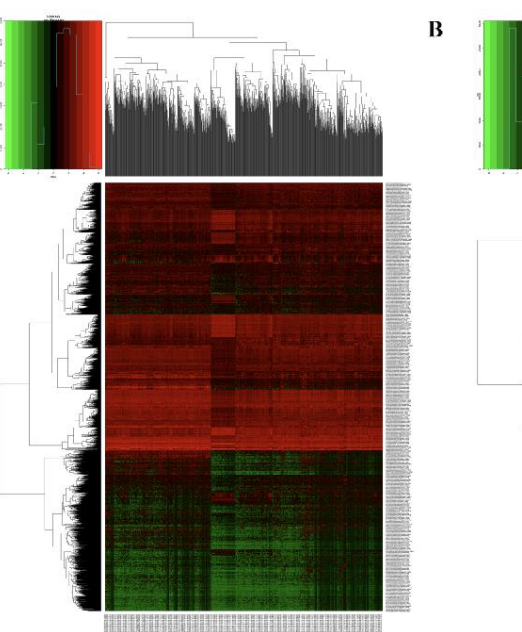

C

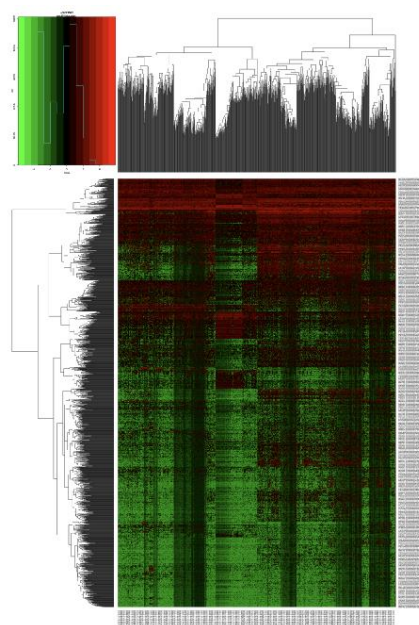

Fig. 3. 
701
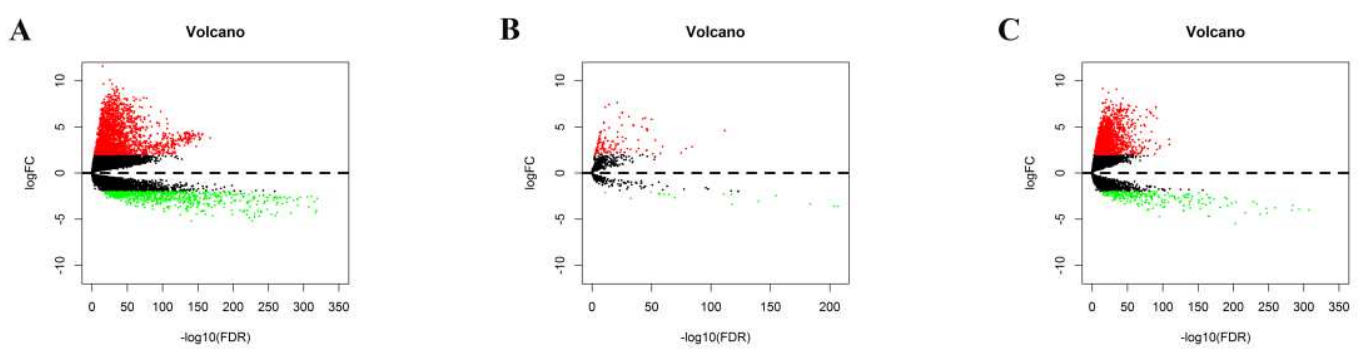

Fig. 4.

703

704

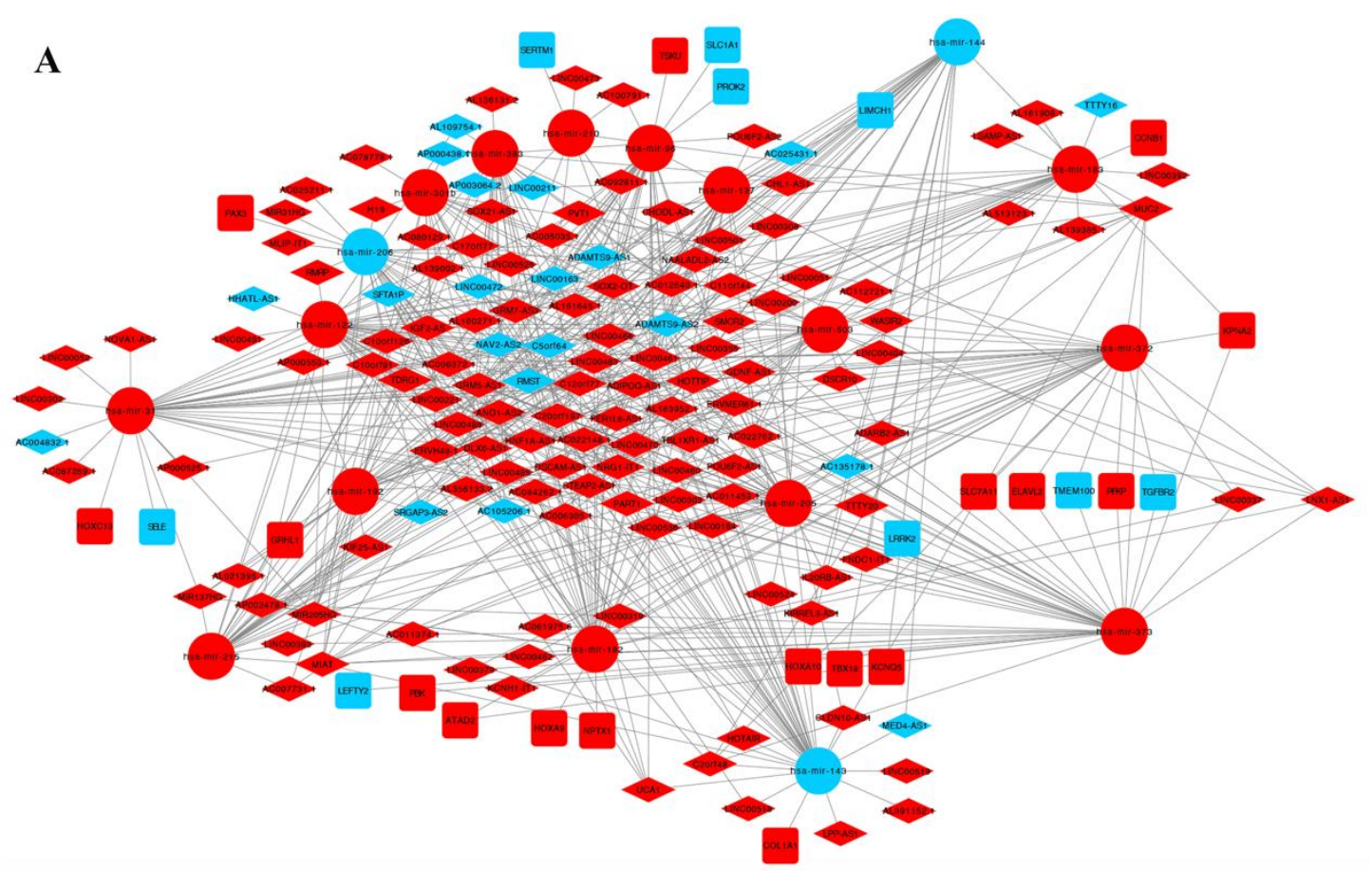

705

B

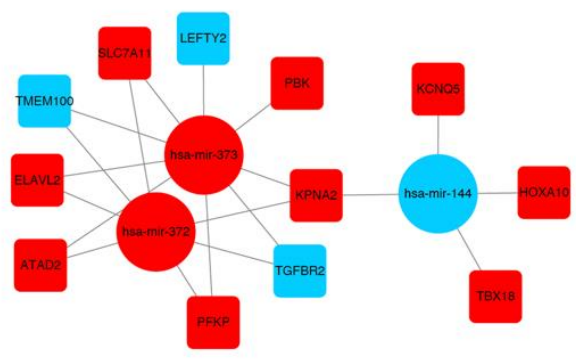

706

707

708

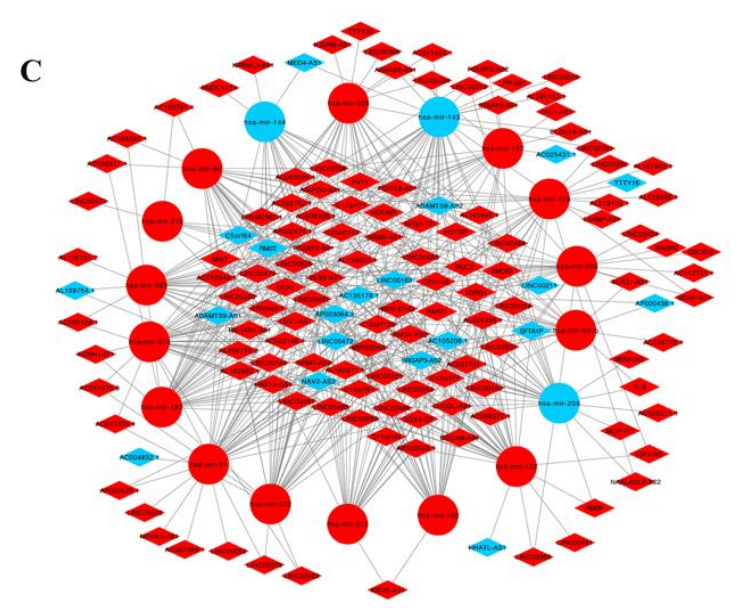

Fig. 5. 
A
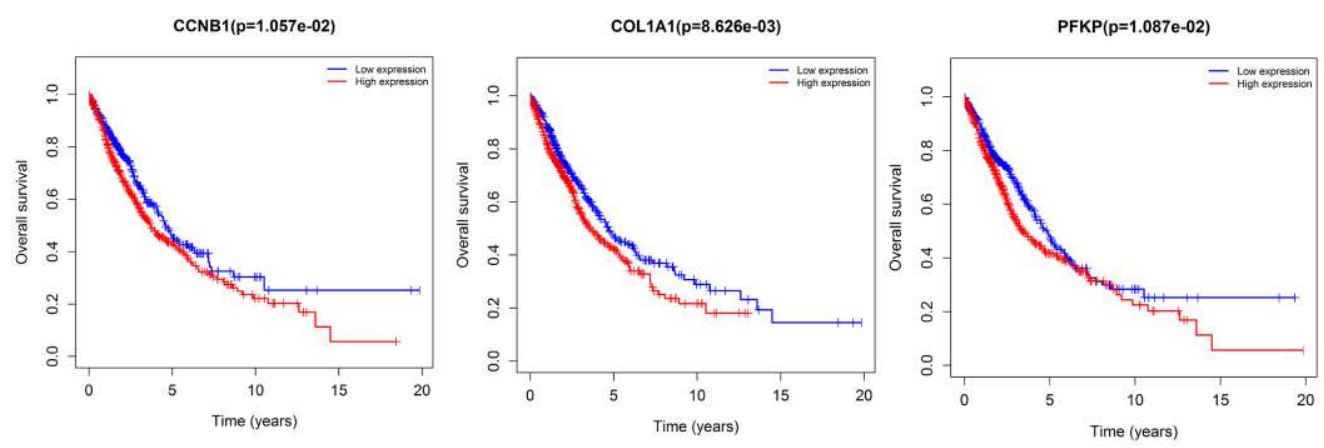

B
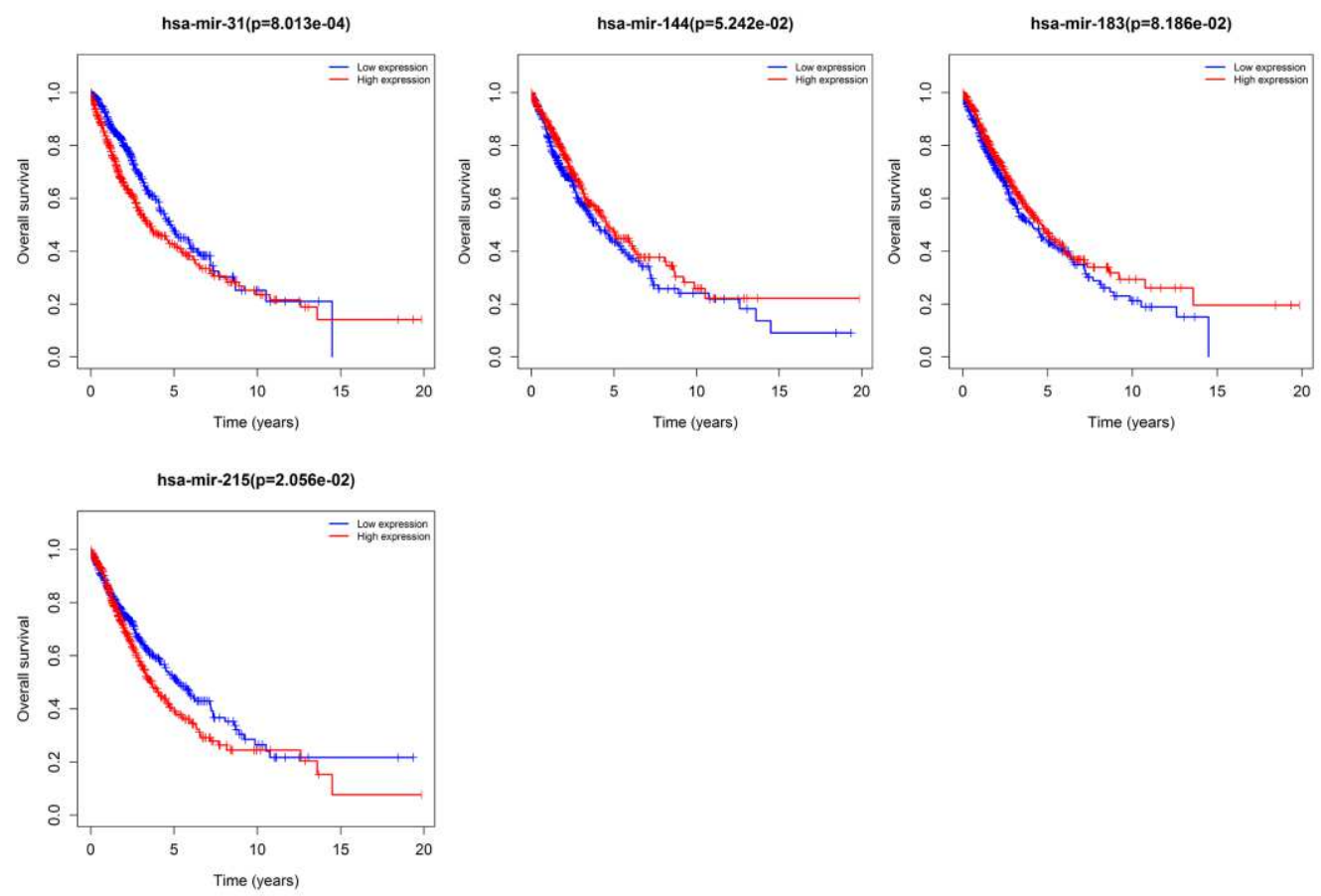

709 

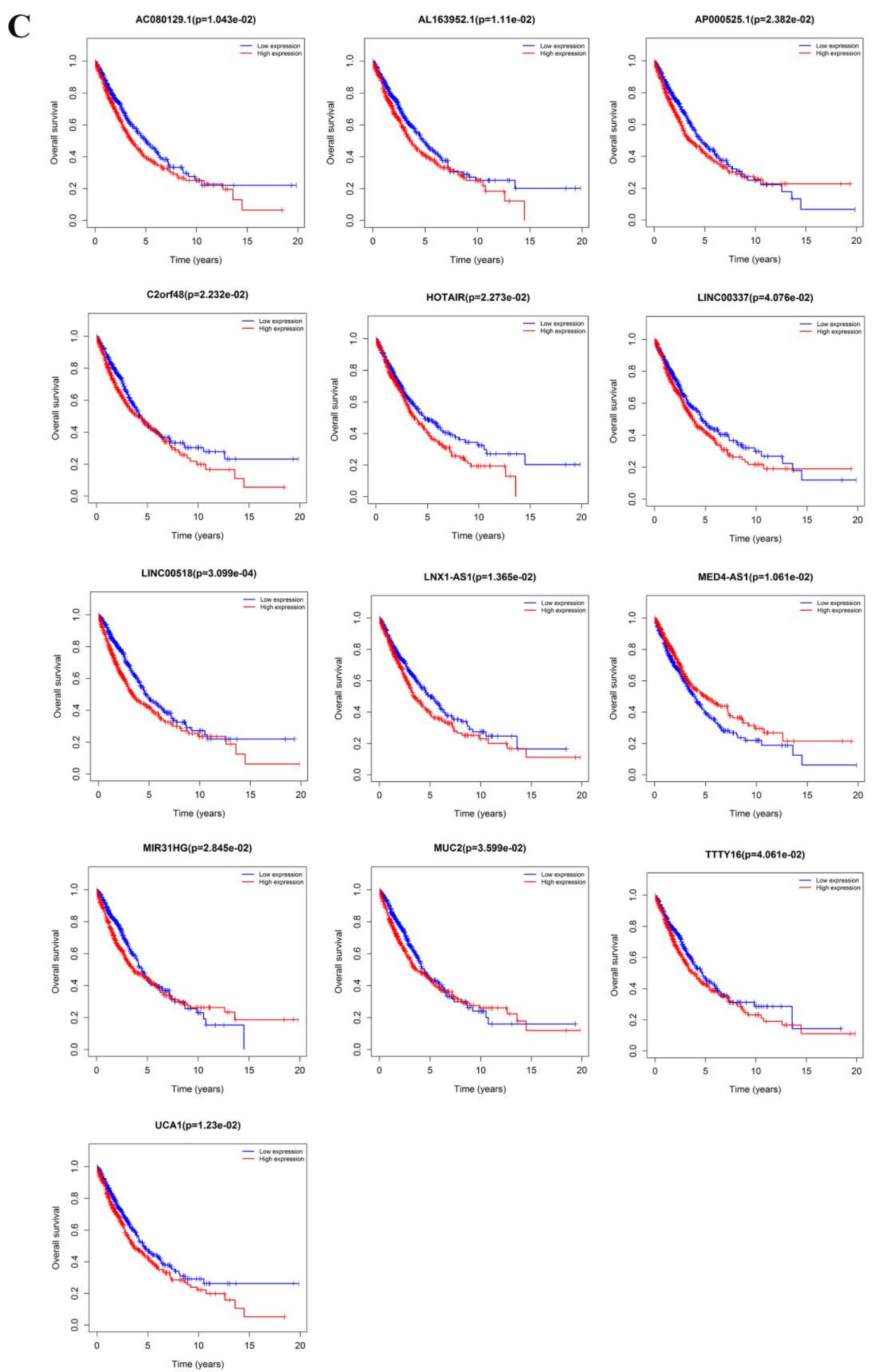

Fig. 6. 
714
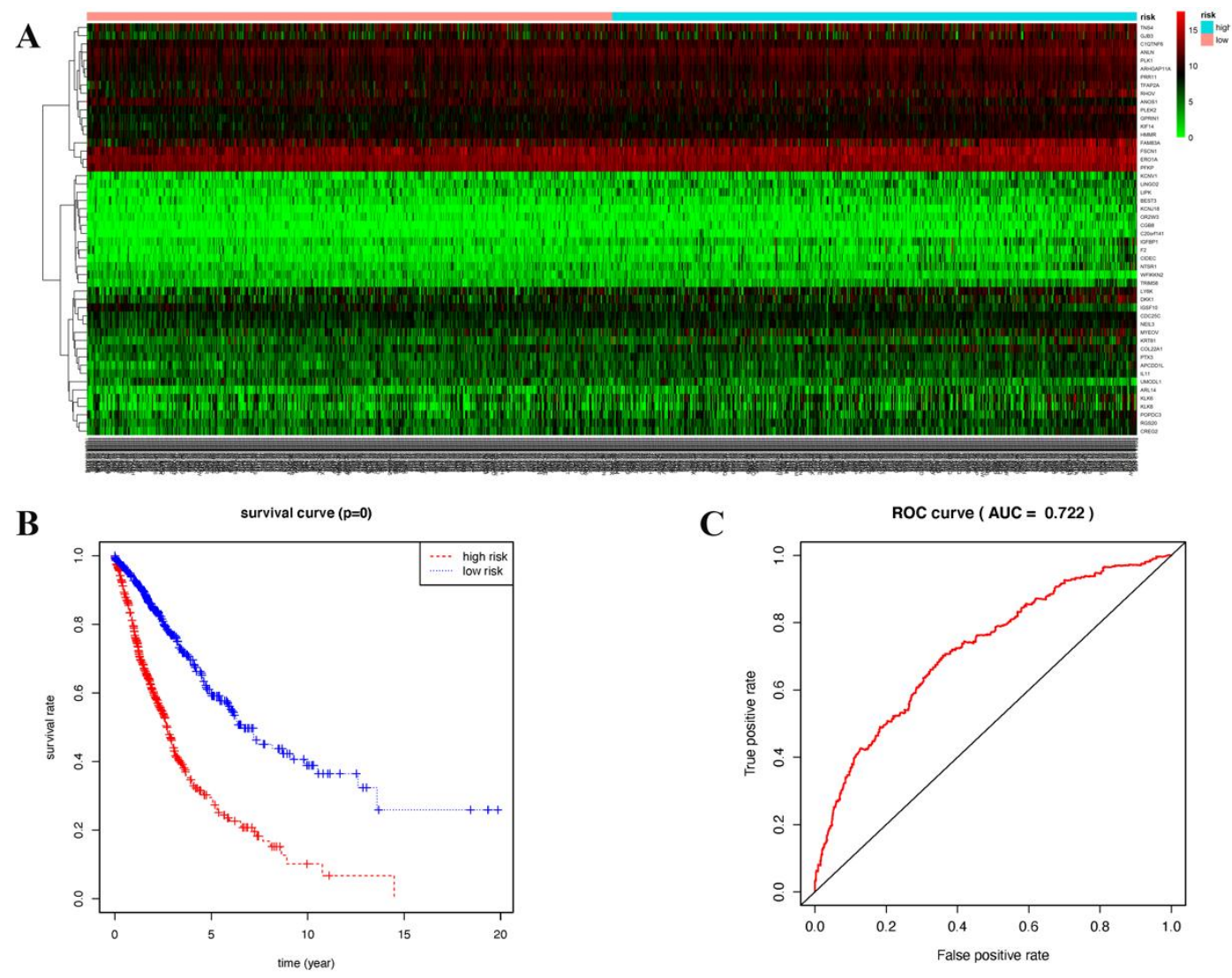

715

716

Fig. 7. 
Table 2. Differentially expressed miRNAs in ceRNA network.

\begin{tabular}{|c|c|c|c|c|c|c|c|}
\hline DEmRNAs & Regulation & $\log F C$ & FDR & DEmiRNAs & Regulation & $\operatorname{logFC}$ & FDR \\
\hline $\begin{array}{c}\text { HOXC13 } \\
\text { PAX3 }\end{array}$ & $\begin{array}{l}\text { upregulation } \\
\text { upregulation }\end{array}$ & $\begin{array}{l}7.900168814 \\
5.030883608\end{array}$ & $\begin{array}{l}9.49 \mathrm{E}-69 \\
7.85 \mathrm{E}-26\end{array}$ & hsa-mir-372 & upregulation & 7.42568468 & 4.90E-15 \\
\hline HOXA10 & upregulation & 4.879826226 & $5.41 \mathrm{E}-63$ & hsa-mir-122 & upregulation & 5.49171687 & 7.80E-11 \\
\hline $\begin{array}{c}\text { PBK } \\
\text { SLC7A11 }\end{array}$ & $\begin{array}{l}\text { upregulation } \\
\text { upregulation }\end{array}$ & $\begin{array}{l}3.892566513 \\
3.758359723\end{array}$ & $\begin{array}{c}1.91 \mathrm{E}-108 \\
9.29 \mathrm{E}-50\end{array}$ & hsa-mir-373 & upregulation & 5.40601511 & $1.35 \mathrm{E}-10$ \\
\hline CCNB1 & upregulation & 3.394316559 & $4.19 \mathrm{E}-136$ & hsa-mir-205 & upregulation & 5.25048736 & $1.55 E-35$ \\
\hline $\begin{array}{l}\text { ELAVL2 } \\
\text { NPTX1 }\end{array}$ & upregulation & 3.36504559 & $\begin{array}{l}8.76 E-24 \\
878 F-19\end{array}$ & hsa-mir-31 & upregulation & 5.00984484 & 1.10E-42 \\
\hline $\begin{array}{l}\text { NPTX1 } \\
\text { KCNQ5 }\end{array}$ & $\begin{array}{l}\text { upregulation } \\
\text { upregulation }\end{array}$ & $\begin{array}{l}2.884592852 \\
2.823401018\end{array}$ & $\begin{array}{l}8.78 \mathrm{E}-19 \\
2.16 \mathrm{E}-42\end{array}$ & hsa-mir-210 & upregulation & 4.60093232 & 1.86E-112 \\
\hline TBX18 & upregulation & 2.78409373 & $1.11 \mathrm{E}-20$ & hsa-mir-301b & upregulation & 3.54614623 & $6.93 E-54$ \\
\hline $\begin{array}{l}\text { KPNA2 } \\
\text { GRHL1 }\end{array}$ & $\begin{array}{l}\text { upregulation } \\
\text { upregulation }\end{array}$ & $\begin{array}{c}2.348067799 \\
2.28610654\end{array}$ & $\begin{array}{l}5.66 \mathrm{E}-97 \\
8.94 \mathrm{E}-55\end{array}$ & hsa-mir-137 & upregulation & 3.42899329 & $1.48 \mathrm{E}-17$ \\
\hline COL1A1 & upregulation & 2.182573341 & $3.09 E-33$ & hsa-mir-96 & upregulation & 2.83954332 & $4.79 E-85$ \\
\hline $\begin{array}{l}\text { ATAD2 } \\
\text { HOXA9 }\end{array}$ & $\begin{array}{l}\text { upregulation } \\
\text { upregulation }\end{array}$ & $\begin{array}{l}2.126839658 \\
2.104643042\end{array}$ & $\begin{array}{l}5.58 \mathrm{E}-96 \\
1.62 \mathrm{E}-18\end{array}$ & hsa-mir-215 & upregulation & 2.74212669 & $2.91 E-15$ \\
\hline TSKU & upregulation & 2.086024777 & $4.92 \mathrm{E}-55$ & hsa-mir-183 & upregulation & 2.65645895 & $7.40 E-80$ \\
\hline $\begin{array}{l}\text { PFKP } \\
\text { TGFBR? }\end{array}$ & upregulation & 2.014985289 & $1.24 \mathrm{E}-66$ & hsa-mir-192 & upregulation & 2.50206211 & $5.75 E-19$ \\
\hline $\begin{array}{l}\text { TGFBR2 } \\
\text { LIMCH1 }\end{array}$ & $\begin{array}{l}\text { downregulation } \\
\text { downregulation }\end{array}$ & $\begin{array}{l}-2.079739895 \\
-2.152042067\end{array}$ & $\begin{array}{c}3.15 \mathrm{E}-144 \\
5.92 \mathrm{E}-81\end{array}$ & hsa-mir-383 & upregulation & 2.47380472 & $7.48 E-06$ \\
\hline PROK2 & downregulation & -2.285552885 & $1.26 \mathrm{E}-52$ & hsa-mir-503 & upregulation & 2.43042528 & $1.39 E-46$ \\
\hline $\begin{array}{l}\text { LEFTY2 } \\
\text { LRRK2 }\end{array}$ & $\begin{array}{l}\text { downregulation } \\
\text { downregulation }\end{array}$ & $\begin{array}{l}-2.382885057 \\
-2.539663204\end{array}$ & $\begin{array}{l}3.17 E-53 \\
2.13 E-71\end{array}$ & hsa-mir-182 & upregulation & 2.14139645 & $3.47 E-58$ \\
\hline SLC1A1 & downregulation & -2.587327755 & $2.95 \mathrm{E}-116$ & hsa-mir-206 & downregulation & -2.1170367 & 8.89E-12 \\
\hline $\begin{array}{c}\text { SELE } \\
\text { SERTM1 }\end{array}$ & $\begin{array}{l}\text { downregulation } \\
\text { downregulation }\end{array}$ & $\begin{array}{l}-2.896579638 \\
-4.526338137\end{array}$ & $\begin{array}{c}1.06 \mathrm{E}-85 \\
4.91 \mathrm{E}-126\end{array}$ & hsa-mir-143 & downregulation & -2.2620671 & $2.13 E-111$ \\
\hline TMEM100 & downregulation & -4.594473407 & $1.59 \mathrm{E}-260$ & hsa-mir-144 & downregulation & -3.3426405 & $2.81 E-184$ \\
\hline
\end{tabular}




\section{Table 3. Differentially expressed lncRNAs in ceRNA network.}

\begin{tabular}{|c|c|c|c|c|c|c|c|c|c|c|c|}
\hline & & gifC & $\ldots$ & & & $\log F C$ & 然 & ncRNA & on & $\log \mathrm{FC}$ & EDR \\
\hline 00392 & & & & & & .58925951 & $20=-1:$ & 92811.1 & & .378492104 & $6.00 \mathrm{E}-14$ \\
\hline $\begin{array}{l}\text { DSCAM-AS1 } \\
\text { POU6F2-AS2 }\end{array}$ & gulation & & & & & 3.579760338 & & 379 & egl & 年 & $7.23 E-05$ \\
\hline & & & & NC00488 & upregulation & 3.496926005 & & 5.1 & ulation & 49829402 & \\
\hline & & & & 02478.1 & & 3.496585224 & & & regulation & 149 & \\
\hline HOTAIR & & & & & & & & & regulation & 2.330161426 & 1735 \\
\hline & & & & & egulation & 3.380 & & & ion & 2.325388201 & $2.07 \mathrm{E}$ \\
\hline & & & & & & & & & regulation & 2.322949207 & 4.33E \\
\hline & & 74 & SE-51 & & & & & AS1 & & 2.271735723 & \\
\hline & & & & & & & & LINC & regulation & 2.266302816 & $34 \mathrm{E}$ \\
\hline Vin & & & & & & & $8.09 E-12$ & & & 25 & \\
\hline & & & & & & & 2.82E-17 & & regulation & 4335212 & $77 \mathrm{E}$ \\
\hline & & & & & & & & & tion & 951 & \\
\hline & & & & & & & & LFP & ion & 251 & $1 \mathrm{E}-(\mathrm{r}$ \\
\hline & & & & & & 34 & $E-19$ & & & & \\
\hline & & & & & & & & 11 & tion & 2.157207561 & $3 E-$ \\
\hline & & & -38 & 2.1 & & & & & & & \\
\hline & & & & & & & & & regulation & 25834 & 76E- \\
\hline & & & & & & & & & & & \\
\hline & & & & & & & & & tion & & $86 \mathrm{E}-\mathrm{C}$ \\
\hline & & & & & & & & & & & \\
\hline & & & & & & & & IVII & tion & 063677441 & 4.45E-24 \\
\hline & & & & & & & & AS1 & tion & 963 & \\
\hline & & & & & & & & & lation & 186 & $1 \mathrm{E}-$ \\
\hline & & & & & & & & 2 & latior & & \\
\hline & & & & & & & & & tion & 894 & $10 \mathrm{E}-6$ \\
\hline & & & & & & & & & ation & & \\
\hline & & & & & & & & $\mathrm{ACO}$ & downre & -2.36 & $3.72 \mathrm{E}-$ \\
\hline & & & & & & & & & a & & \\
\hline & & & & & & & & & downi & & 0.7 \\
\hline & & & & & & & & & lation. & & \\
\hline & & & & & & & & & Iation & 5883 & $E-6$ \\
\hline & & & & & & & & & & & \\
\hline & & & & & & & & & & & \\
\hline & & & & & & & & & & & \\
\hline & & & & & & & & & & 3373 & \\
\hline & & & & & & & & & & & \\
\hline & & & & & & & & & & & \\
\hline & & & & & & & & & inregulation & & \\
\hline & & & & & & & & & vnregulation & 480 & \\
\hline & & & & & & & & & ont & 400 & \\
\hline & & & & & & & & & & & \\
\hline & & & & & & & & & & & \\
\hline
\end{tabular}


Table 4. Differentially expressed miRNAs targeting mRNAs in the ceRNA network.

\section{MIRNA MRNA}

hsa-mir-372 TGFBR2, ELAVL2, PFKP, TMEM100, KPNA2, ATAD2, SLC7A11

hsa-mir-373 KPNA2, LEFTY2, ELAVL2, ATAD2, TGFBR2, PBK, PFKP, SLC7A11, TMEM100

hsa-mir-144 HOXA10, TBX18, KCNQ5, KPNA2

hsa-mir-210 SERTM1

hsa-mir-31 HOXC13, SELE

hsa-mir-96 TSKU, SLC1A1, PROK2

hsa-mir-182 NPTX1, HOXA9

hsa-mir-137 LIMCH1

hsa-mir-183 CCNB1

hsa-mir-192 GRHL1

hsa-mir-205 LRRK2

hsa-mir-143 COL1A1

723 Table. 4 
727 Table 5. Differentially expressed lncRNAs targeting miRNAs in the ceRNA network.

\begin{tabular}{|c|c|c|c|c|c|c|}
\hline 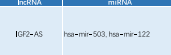 & 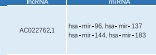 & 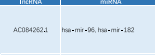 & $-m=$ & $-\ldots=$ & 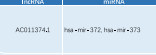 & 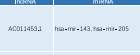 \\
\hline$\ldots$ & $y=$ & 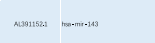 & 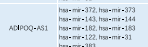 & 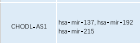 & $-\ldots$ & wamex -.... \\
\hline 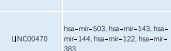 & com $\equiv$ & $-m=-\cdots$ & 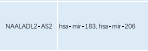 & $y=$ & 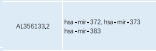 & 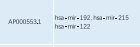 \\
\hline Fit & 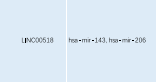 & wa $=$ & wates & $m=-\cdots$ & 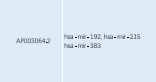 & $=$ \\
\hline & 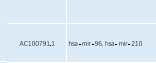 & $-m=$ & . & $-3=$ & . & 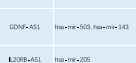 \\
\hline 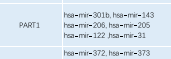 & 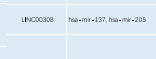 & $-\cdots$ & $-m$ & & 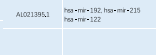 & \\
\hline & $-m$ & 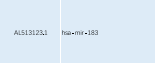 & 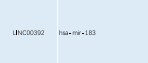 & $\cdots-\cdots$ & $=0$ & $m=$ \\
\hline 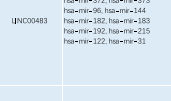 & 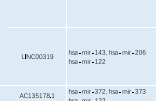 & nann & 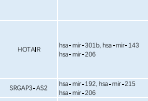 & 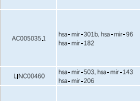 & 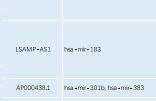 & 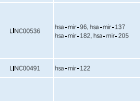 \\
\hline 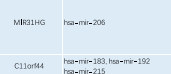 & ${ }_{\text {war }}=$ & 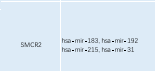 & . & $\ldots$ & $=$ & 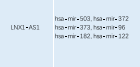 \\
\hline & 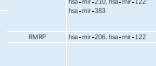 & somenn $=$ & 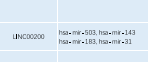 & - & mame $=$ & $=$ \\
\hline & & $-m$ & 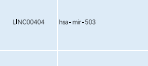 & & 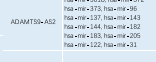 & $=$ \\
\hline 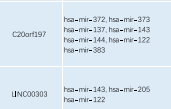 & $=$ & 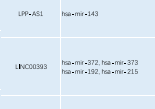 & $\ldots$ & $=0$ & $=$ & man $=3$ \\
\hline 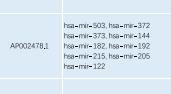 & $\ldots$ & weres $=0$ & $\cdots-3=$ & nem & 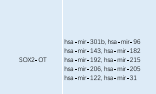 & $-3=$ \\
\hline 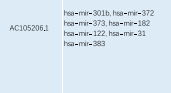 & wost $=\ldots$ & 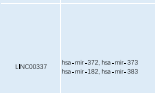 & -3 & $=$ & $=\ldots$ & $\cdots$ \\
\hline - & 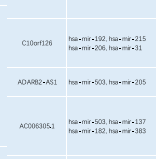 & 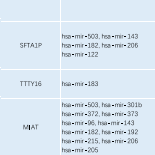 & 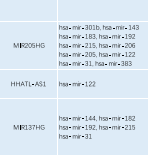 & 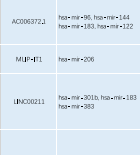 & 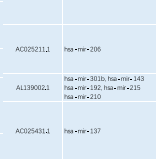 & . \\
\hline 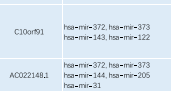 & 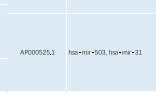 & $=$ & $\operatorname{mox}=$ & . & $\mathrm{mem}=$ & $=\ldots$ \\
\hline
\end{tabular}


729 Table 6. Significant genes demonstrated in univariate Cox regression model $(\mathrm{P}<0.001)$

\begin{tabular}{|c|c|c|c|}
\hline gene & HR & 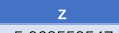 & pvalue \\
\hline CIDEC & 1.130155519 & 5.068559547 & $4.01 E-07$ \\
\hline OR2W3 & 1.159398455 & 4.734716363 & $2.19 \mathrm{E}-06$ \\
\hline TRIM58 & 1.114151415 & 4.463796912 & $8.05 \mathrm{E}-06$ \\
\hline LIPK & 1.097950277 & 4.302133412 & $1.69 \mathrm{E}-05$ \\
\hline BEST3 & 1.101691764 & 4.244695096 & $2.19 \mathrm{E}-05$ \\
\hline C1QTNF6 & 1.21473153 & 4.199190658 & -05 \\
\hline IGFBP1 & 1.094122986 & 4.182470294 & $2.88 \mathrm{E}-05$ \\
\hline DKK1 & 1.08072014 & 4.136233568 & 3.53E-05 \\
\hline ARL14 & 1.079831726 & 4.064975749 & $4.80 \mathrm{E}-05$ \\
\hline FAM83A & 1.089982158 & 4.040543173 & $5.33 \mathrm{E}-05$ \\
\hline & 1.088928234 & & \\
\hline C20orf141 & 1.144831011 & 3.963106674 & \\
\hline ANLN & 1.169526571 & 3.927598316 & \\
\hline LINGO2 & 1.085344834 & 3.834882417 & 0.000125624 \\
\hline KCNJ18 & 1.100206952 & 3.806435294 & 0.000140984 \\
\hline COL22A1 & 1.088747223 & 3.798463907 & 0.000145596 \\
\hline APCDD1L & 1.087012549 & 3.770075508 & 0.000163198 \\
\hline PLEK2 & 1.143716829 & 3.696100107 & 0.000218937 \\
\hline GPRIN1 & 1.181742559 & 3.691616261 & 0.000222833 \\
\hline PLK1 & 1.17087653 & 3.626260431 & 0.000287555 \\
\hline NEIL3 & 1.130993732 & 3.617155528 & 0.000297858 \\
\hline HMMR & 1.178465138 & 3.579578006 & 0.00034415 \\
\hline RHOV & 1.100478191 & 3.5764464425 & 0.000348297 \\
\hline KIF14 & 1.14936952 & 3.572023027 & 0.000354234 \\
\hline PTX3 & 1.106026777 & 3.5706393 & 0.000356111 \\
\hline WFIKKN2 & 0.889481471 & -3.5577005287 & 0.000361084 \\
\hline PRR11 & 1.171569877 & 3.564783346 & 0.000364157 \\
\hline KCNV1 & 1.074663227 & 3.561295522 & 0.000369029 \\
\hline RGS20 & 1.091826086 & 3.550639745 & 0.000384296 \\
\hline TFAP2A & 1.102128673 & 3.509734411 & 0.000448554 \\
\hline ERO1A & 1.200652464 & 3.509685404 & 0.000448637 \\
\hline IGSF10 & 0.90 & -3.49 & 0478756 \\
\hline LYGK & 1.0644751 & 3.48 & 0.000498008 \\
\hline PFK & 1.19 & & \\
\hline ANOS1 & 0.891564746 & -3.45 & \\
\hline CGB8 & 1.1065 & 3.441381498 & 3752 \\
\hline $\mathrm{CDC25C}$ & 1.1699 & 3.439991943 & 0.0 \\
\hline MYEOV & 1.0662 & 3.430010983 & 557 \\
\hline F2 & 1.078 & 3.428497983 & 06931 \\
\hline FSCN1 & & & \\
\hline & 1.048 & 3.4 & \\
\hline KR & & & 6716027 \\
\hline CREC & 1.076 & & \\
\hline KLK6 & & 3.3603 & \\
\hline GJ & & 3.34776 & \\
\hline TNS4 & $1.065^{3}$ & 3.341780834 & 0.000832428 \\
\hline UMODL1 & 0.93069226 & -3.341348721 & 0.000833724 \\
\hline POPDC3 & 1.061240666 & 3.337769753 & 0.000844537 \\
\hline & 1.100268069 & 3.32036034 & 0.000899013 \\
\hline ARHG & & 3.299473315 & 00968664 \\
\hline
\end{tabular}


Table 7. 18 mRNAs expression profiles for prediction of overall survival in lung cancer by multivariate Cox regression.

\begin{tabular}{|c|c|c|}
\hline Gene & HR & P-value \\
\hline ANOS1 & 0.91977 & 0.029259 \\
\hline TFAP2A & 1.1122 & 0.004444 \\
\hline FAM83A & 1.08183 & 0.001032 \\
\hline IGSF10 & 0.93809 & 0.056385 \\
\hline WFIKKN2 & 0.93087 & 0.033323 \\
\hline PTX3 & 1.09537 & 0.0053 \\
\hline GJB3 & 0.9496 & 0.085902 \\
\hline COL22A1 & 1.05869 & 0.020412 \\
\hline LY6K & 1.03246 & 0.117689 \\
\hline KLK6 & 0.95278 & 0.066225 \\
\hline FSCN1 & 1.07893 & 0.097713 \\
\hline KLK8 & 1.0358 & 0.151775 \\
\hline TRIM58 & 1.10451 & $6.36 E-05$ \\
\hline KCNV1 & 1.04437 & 0.048754 \\
\hline C20orf141 & 0.93072 & 0.100641 \\
\hline IGFBP1 & 1.06865 & 0.010148 \\
\hline LINGO2 & 1.04839 & 0.051753 \\
\hline CIDEC & 1.10421 & 0.000968 \\
\hline
\end{tabular}




\section{Figures}
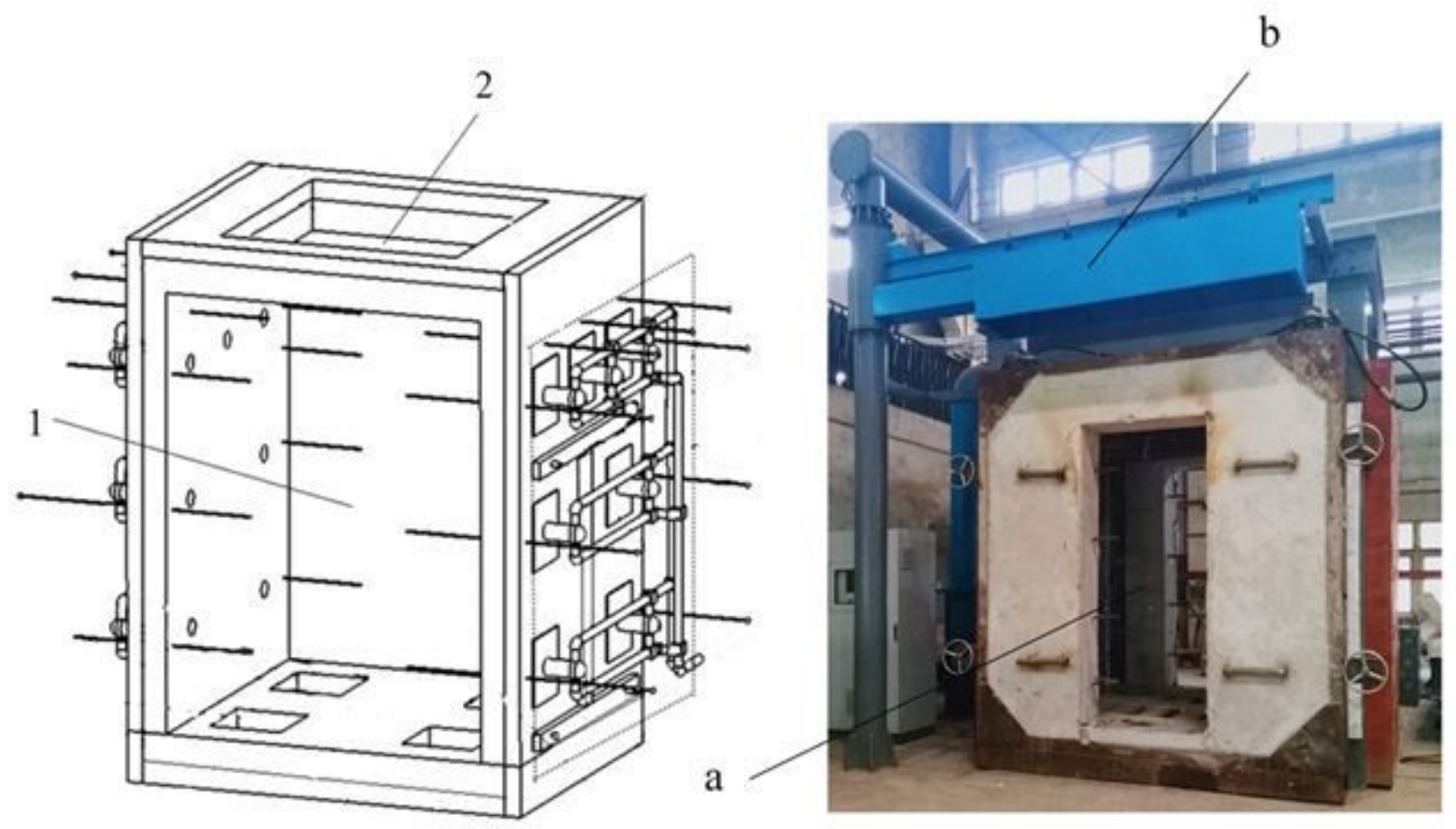

Figure 1

The test equipment system of smoke. (A) The sketch map of the equipment system. The combustion chamber was marked by " 1 ". The smoke collecting window was marker by " 2 ". (B) The practicality picture of the system. The smoke collecting window was marker by "a". The smoke collecting window was marker by "b". 


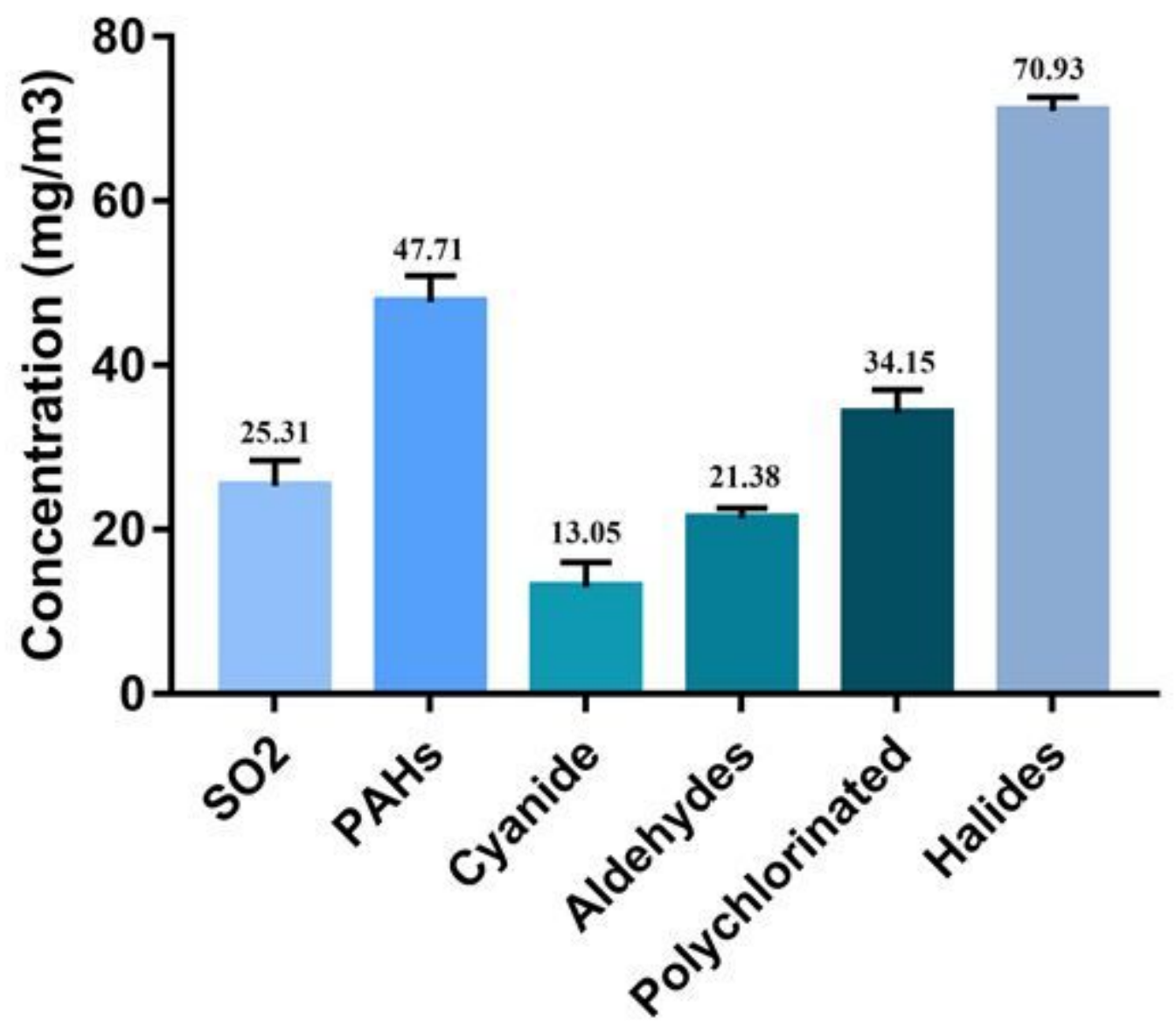

Figure 2

The toxic smoke concentration of the door-flame experiment. The number on the column marked the arithmetic mean concentration of the smoke and bar indicated the mean \pm SD.

$\mathbf{A}$

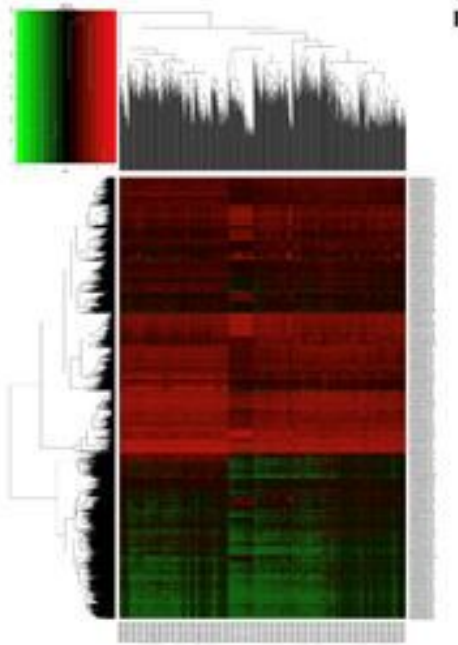

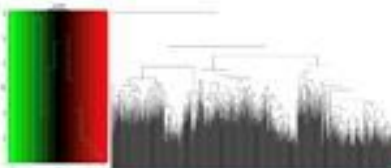

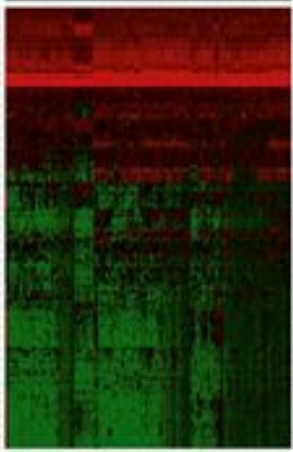

C
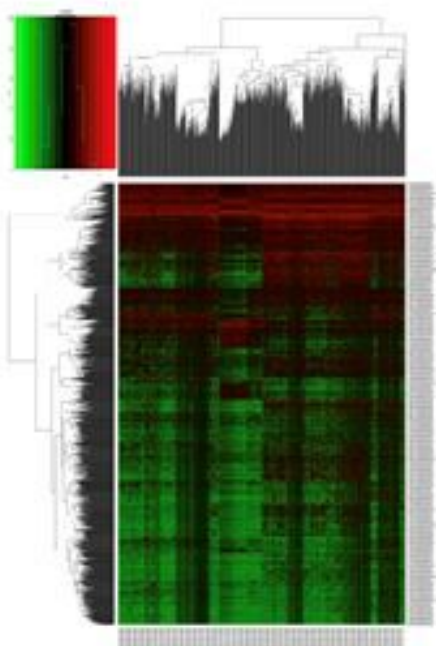

Figure 3 
The heatmap of the differently expressed RNAs. (A) The heatmap of differently expressed mRNA. The green box showed mRNA was down-regulated and red box showed mRNA up-regulated. (B) The heatmap of differently expressed miRNA. The green box showed miRNA was down-regulated and red box showed miRNA up-regulated. (C) The heatmap of differently expressed IncRNA. The green box showed IncRNA was down-regulated and red box showed IncRNA up-regulated.
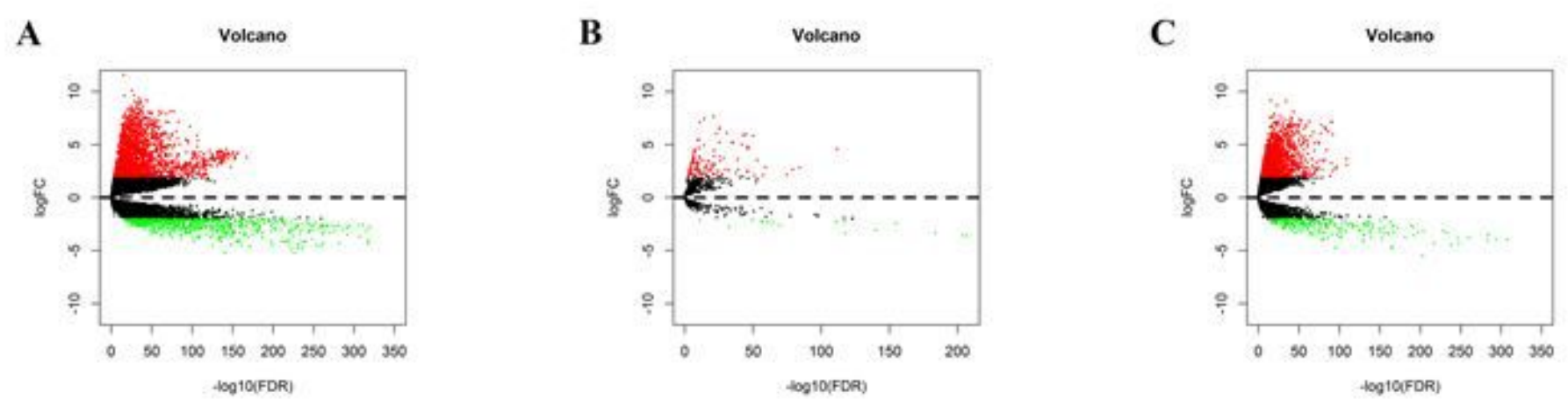

\section{Figure 4}

Differentially expressed RNAs in lung cancer are visualized by volcano plots. The red dots show upregulated genes while the green dots show downregulated genes. (A) Differentially expressed mRNAs in lung cancer. (B) Differentially expressed miRNAs in lung cancer. (C) Differentially expressed IncRNAs in lung cancer. 


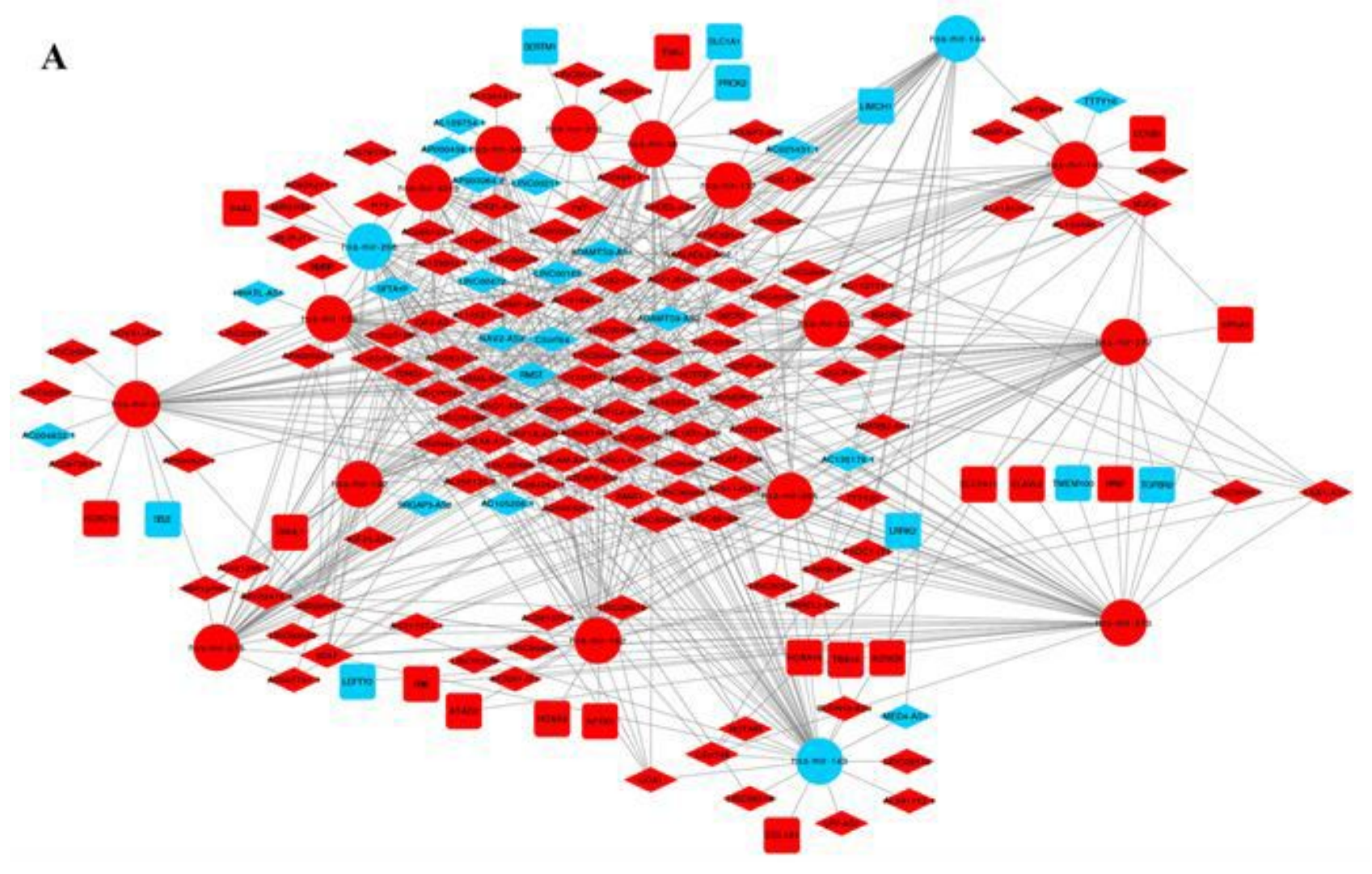

B

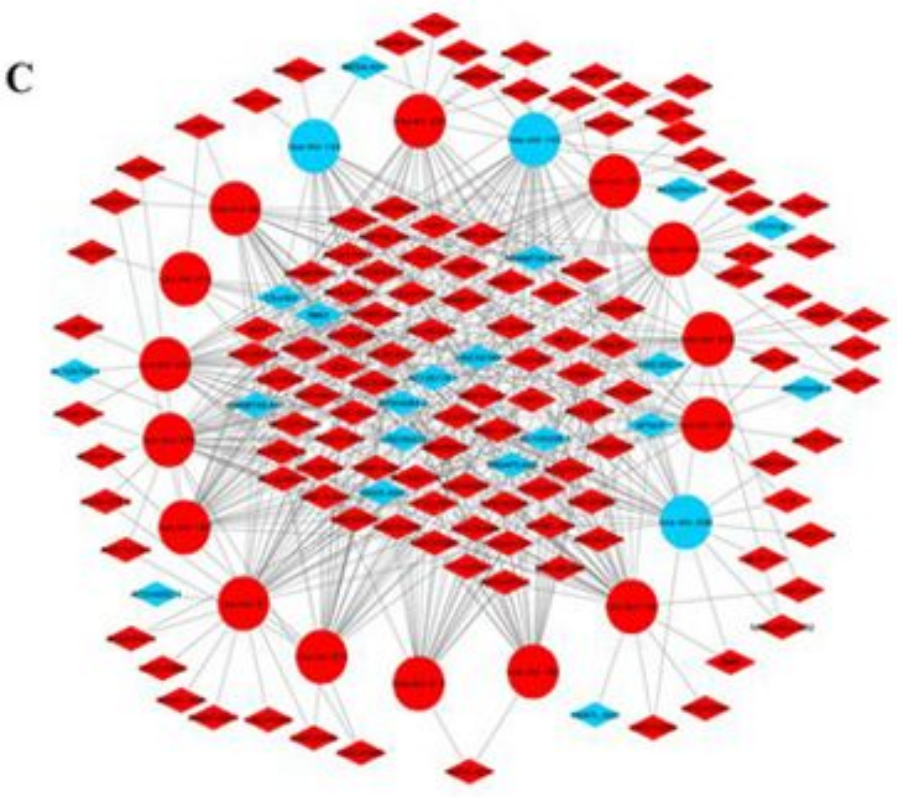

Figure 5

The ceRNA network of lung cancer. mRNA was in rounded rectangle, miRNA was in round, IncRNA was in diamond. The blue show downregulated gene while red show upregulated gene. (A) ceRNA network that involve mRNA, miRNA and IncRNA. (B) The RNAs network between miRNA and mRNA. (C) The RNAs network between miRNA and IncRNA. 
A

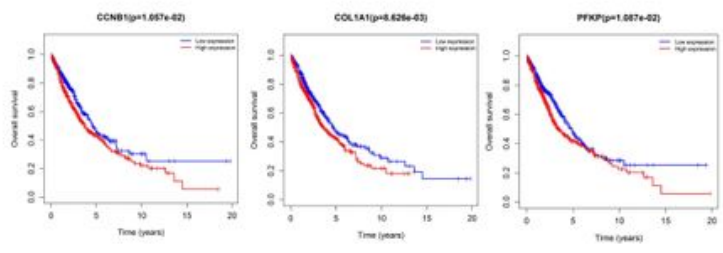

B
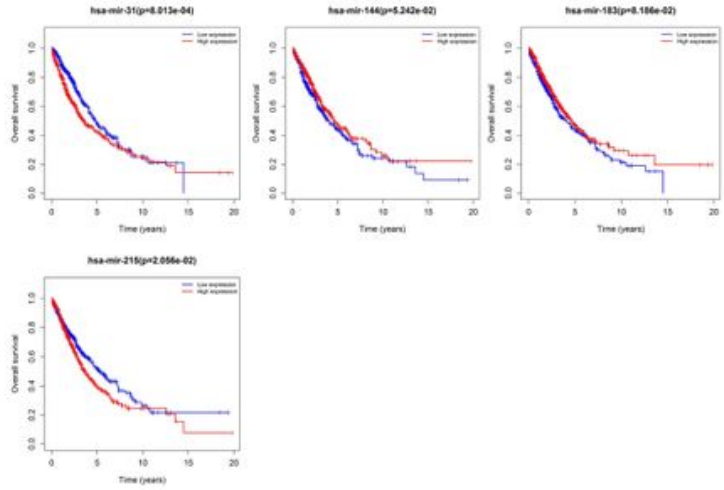

C
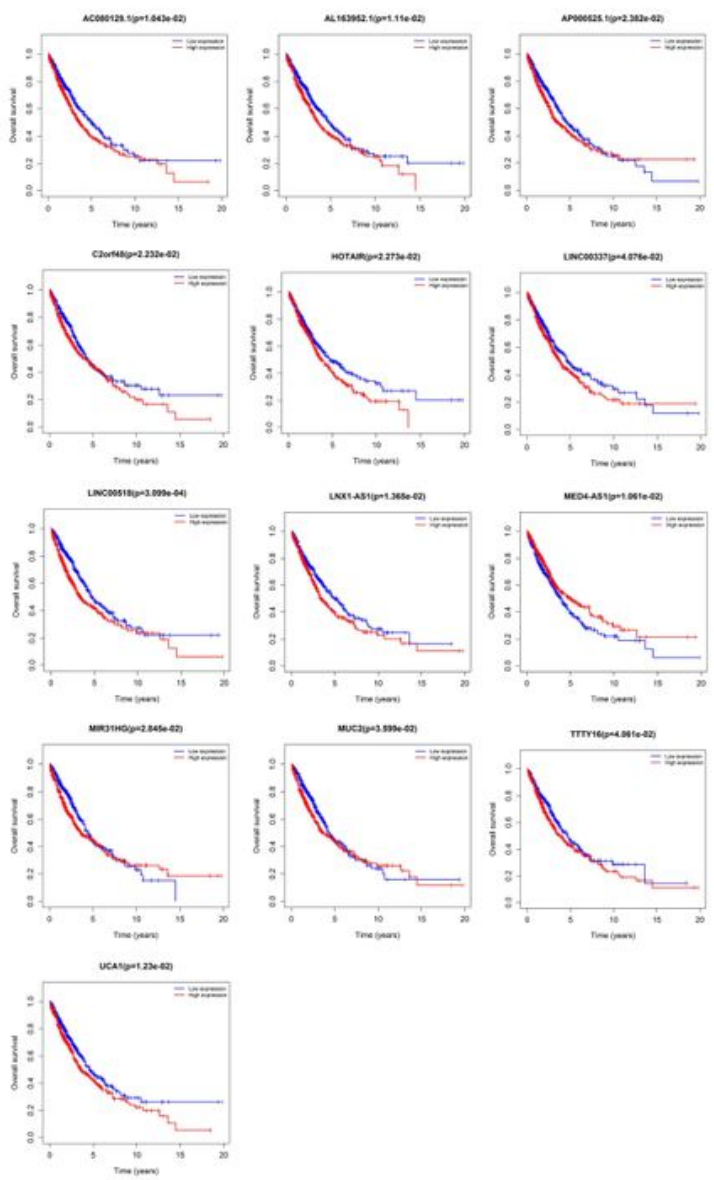

\section{Figure 6}

The Kaplan-Meier plots of differentially expressed RNAs in the ceRNA network which are also related to high-grade, stages, and overall survival $(P<0.01)$. (A) The survival curve of mRNAs. (B) The survival curve of miRNAs. (C) The survival curve of IncRNAs. 

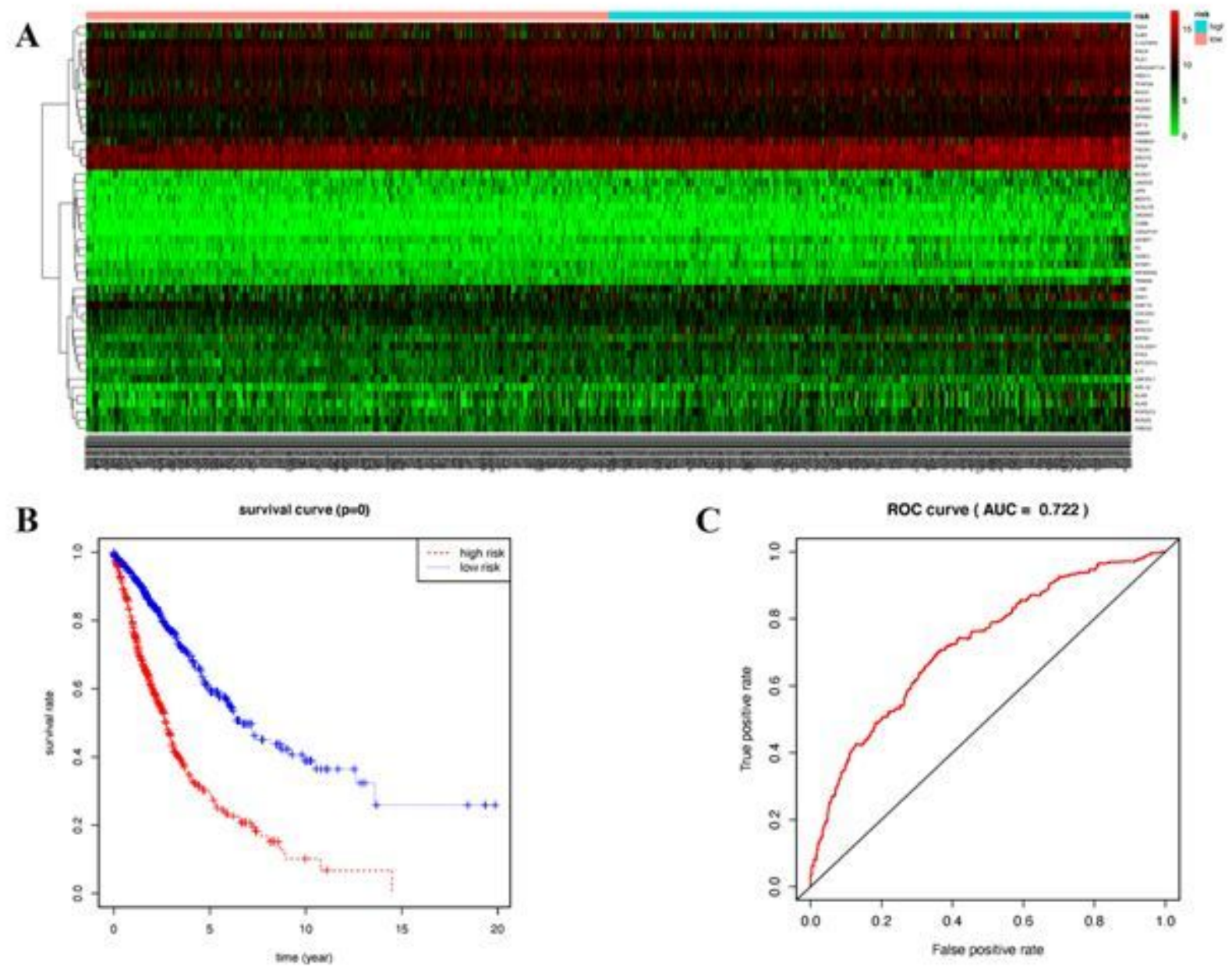

Figure 7

Thus, there is more benefit to detect lung cancer biomarkers for firefighters. 